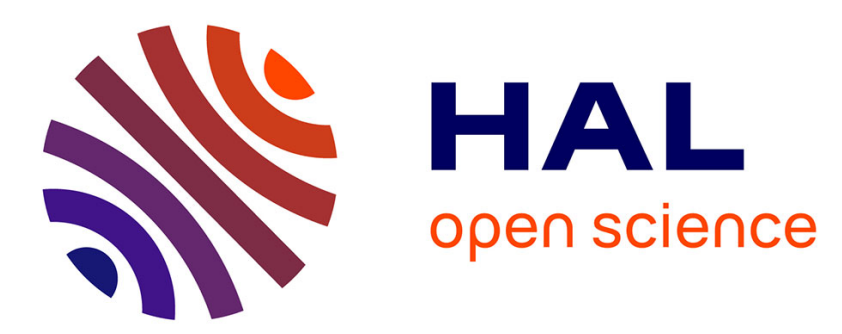

\title{
Semi phenomenological modelling of the behavior of TRIP steels
}

\author{
Régis Kubler, Marcel Berveiller, Pascal Buessler
}

\section{To cite this version:}

Régis Kubler, Marcel Berveiller, Pascal Buessler. Semi phenomenological modelling of the behavior of TRIP steels. International Journal of Plasticity, 2011, 27 (3), pp.299-327. 10.1016/j.ijplas.2010.05.002 . hal-01021823

\section{HAL Id: hal-01021823 \\ https://hal.science/hal-01021823}

Submitted on 30 Aug 2017

HAL is a multi-disciplinary open access archive for the deposit and dissemination of scientific research documents, whether they are published or not. The documents may come from teaching and research institutions in France or abroad, or from public or private research centers.
L'archive ouverte pluridisciplinaire HAL, est destinée au dépôt et à la diffusion de documents scientifiques de niveau recherche, publiés ou non, émanant des établissements d'enseignement et de recherche français ou étrangers, des laboratoires publics ou privés. 


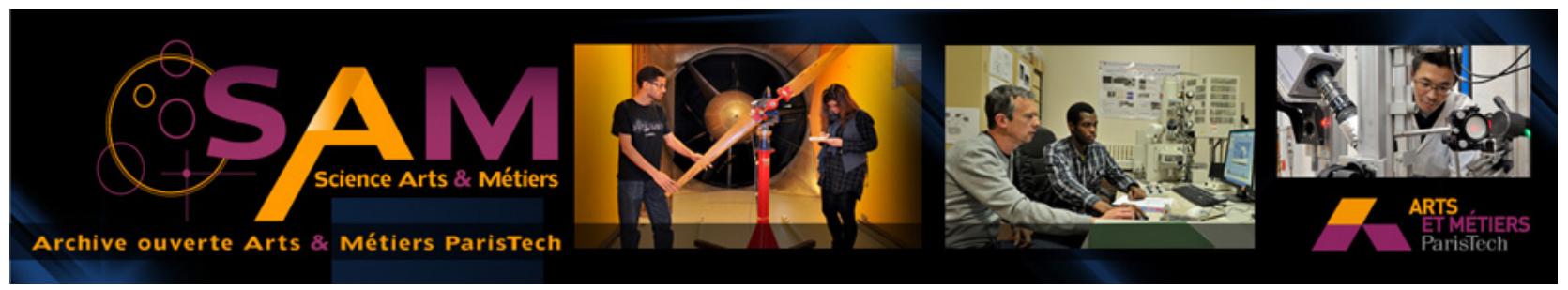

Science Arts \& Métiers (SAM)

is an open access repository that collects the work of Arts et Métiers ParisTech researchers and makes it freely available over the web where possible.

This is an author-deposited version published in: http://sam.ensam.eu

Handle ID: .http://hdl.handle.net/10985/8336

\section{To cite this version :}

Régis KUBLER, Marcel BERVEILLER, Pascal BUESSLER - Semi phenomenological modelling of the behavior of TRIP steels - International Journal of Plasticity n²7, p.299-327 - 2011 


\title{
Semi phenomenological modelling of the behavior of TRIP steels
}

\author{
R.F. Kubler ${ }^{\mathrm{a}, *}$, M. Berveiller ${ }^{\mathrm{b}}$, P. Buessler ${ }^{\mathrm{c}}$ \\ ${ }^{a}$ Arts et Metiers ParisTech, Mecasurf, 2 cours des Arts et Métiers, 13617 Aix-en-Provence Cedex 1, France \\ ${ }^{\mathrm{b}}$ Arts et Metiers ParisTech, LPMM, CNRS - Université de Metz, 4 rue Augustin Fresnel, 57070 Metz Cedex, France \\ ${ }^{\mathrm{c}}$ ArcelorMittal Maizieres Research, Voie Romaine, 57283 Maizières-lès-Metz, France
}

Keywords:

Martensite

Phase transformation

Micromechanics

TRIP effect

\begin{abstract}
A B S T R A C T
A new semi-phenomenological model is developed based on a mean-field description of the TRIP behavior for the simulation of multiaxial loads. This model intends to reduce the number of internal variables of crystalline models that cannot be used for the moment in metal forming simulations. Starting from local and crystallographic approaches, the mean-field approach is obtained at the phase level with the concept of Mean Instantaneous Transformation Strain (MITS) accompanying martensitic transformation. Within the framework of the thermodynamics of irreversible processes, driving forces, martensitic volume fraction evolution and an expression of the TRIP effect are determined for this new model. A classical self-consistent scheme is used to model the behavior of multiphased TRIP steels. The model is tested for cooling at constant loads and for multiaxial loadings at constant temperatures. The predictions reproduce the increase in ductility, the dynamic softening effect and the multiaxial behavior of a multiphased TRIP steel.
\end{abstract}

\section{Introduction}

TRIP (Transformation Induced Plasticity) aided steels offer an excellent combination of strength and ductility at low cost. Thanks to a specific metallurgy and to selective heat treatments, the obtained microstructures are composed of several phases: thermodynamically stable ferrite, bainite, martensite and metastable austenite where the TRIP effect takes place through martensitic phase transformation. The important constituent, the retained austenite, represents usually $10-20 \%$ of the complete microstructure of a TRIP aided steel grade. TRIP effect is also observed in entirely austenitic steel grades such as AISI301 (Berrahmoune et al., 2006). Metastable austenite exhibits a first order non-diffusive martensitic phase transformation when a thermomechanical load is applied. The resulting mechanical response is a transformation strain oriented by the internal and applied stresses. Components made of TRIP aided or austenitic steel grades are generally manufactured by metal forming. During forming processes, different loading paths are experienced from shear to biaxial expansion.

For cooling under no macroscopic stress, martensite transformation starts at $M_{S}$ temperature. Above the $M_{S}^{\sigma}$ temperature, a competition between martensite transformation and plastic flow in austenite exists. Above a critical temperature $M_{d}$, plastic flow in austenite is the major deformation mechanism consolidating the austenitic phase, thus preventing any martensite transformation. The diagram presented in Fig. 1 is a schematic representation of the critical stress for transformation vs. temperature. Two domains exist:

$-M_{S}<T<M_{S}^{\sigma}$ : the critical stress increases linearly with temperature. Transformation precedes plastic flow in austenite. It is called the stress assisted transformation.

\footnotetext{
* Corresponding author. Tel.: +33 442938195; fax: +33 442938115.

E-mail address: regis.kubler@ensam.eu (R.F. Kubler).
} 


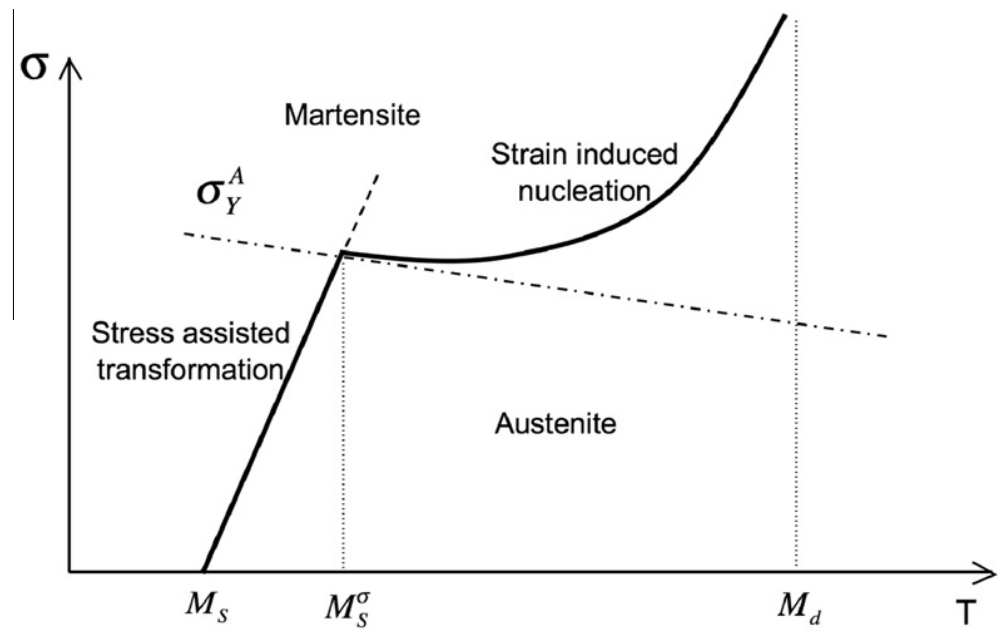

Fig. 1. Critical stress for martensitic transformation as a function of temperature.

- $M_{S}^{\sigma}<T<M_{d}$ : since $\sigma>\sigma_{y}^{A}$, $\sigma_{y}^{A}$ being the yield stress of austenite, plastic flow precedes transformation. It is strain induced transformation.

The local change in crystallographic structure from austenite (FCC) to martensite (BCT) is accompanied by a homogeneous strain of the crystal lattice with a major deviatoric component. This strain is the Bain strain $\varepsilon^{B}$ (4\% of volume change and $20 \%$ of shear strain in carbon steels). Since the Bain strain is incompatible, a lattice invariant strain exists in order to accommodate the internal stresses. Due to the high symmetry of the austenitic lattice, 24 crystallographically possible martensitic variants may be formed with differently oriented transformation strains. From a macroscopic mechanical point of view, TRIP aided steels exhibit an extra strain hardening when submitted to a mechanical load. The formation of martensite consolidates the structure and delays the onset of ductility loss. As far as control variables are concerned, the formation of martensite is influenced by the strain rate (Jimenez et al., 2009), temperature (Tourki et al., 2005) and loading path (Lebedev and Kosarchuk, 2000; Furnemont, 2003). The strain rate dependency is not examined in this study and the mechanical and transformation behaviors are assumed time independent.

Besides hardening, a significative increase in plastic flow known as transformation plasticity is exhibited. Transformation plasticity encompasses two mechanisms:

The Magee effect is a stress oriented variant selection mechanism implying the orientation of the transformation strain with respect to the local stress tensor. Under cooling without any (local and global) stress, no macroscopic transformation strain occurs with the exception of its volumic component. For an applied deviatoric stress during cooling, only the variants with the best orientation with respect to the stress can be potentially activated. It is the main deformation mechanism in shape memory alloys.

The Greenwood Johnson effect (GJ) takes into account the inelastic accommodation of the Bain transformation strain in both martensitic and austenitic phases. Leblond et al. (1989) explain the GJ effect by the generation of microscopic internal stresses due to the volume change between martensite and austenite that trigger plastic flow in the weakest phase. Thus the local stress has an orientation effect on the microscopic plastic strain.

Transformation Induced Plasticity (TRIP) is a phenomenon that has been widely studied and modeled at different length scales in steels. Concerning martensitic transformation, similar interesting approaches have been developed in other materials such as shape memory alloys (Patoor and Berveiller, 1997). At the nanoscopic scale, martensitic transformation is described by atomistic models (Wang, 1997). These models are useful to understand the physics of phase transformation in order to calibrate more accurately some phenomenological models. At the microscopic level, the selective nucleation of martensite platelets can be described within a single crystal using crystallographic theories to calculate the transformation strain (Wechsler et al., 1953; Bowles and Mackenzie, 1954). Similar to dislocation motion on specific glide systems, martensitic transformation occurs along specific transformation directions and habit planes defining 24 martensitic variants. The crystallographic representation is coupled to the problem of an inhomogeneous inclusion with moving boundary as developed by Sabar and Berveiller (1991). Some authors are also interested in the inner constituents of platelets (twins, sub-variants) (Niclaeys et al., 2002). Those models account for crystallographic textures of materials through a representative distribution function of crystals using polycrystalline scale transition methods (Cherkaoui et al., 2000; Kubler et al., 2003; Turteltaub and Suiker, 2006; Petit et al., 2007; Kouznetsova and Geers, 2008). At a larger scale (mesoscopic), the material can be seen as a multiphased microstructure and TRIP aided steels are looked at as composites with an evolving microstructure. The thermomechanical behavior is described per phase and scale transition methods are also used. At the macroscopic scale, a large amount of work has been dedicated to the development of phenomenological/empirical models based mainly on the global 
response of the material. Among all the models, scale transitions techniques enable the use of more physical descriptions, but with a certain computational cost. For a direct complete metal forming simulation, crystallographic or atomistic models are, for the moment, unsuitable. The challenge is to develop semi-phenomenological models, not too reductive, considering a mean instantaneous transformation strain over a transforming domain of volume fraction $\dot{f}=\dot{V} / V$.

Among models to describe the transformation kinetics, there are phenomenological models function of temperature (Koistinen and Marburger, 1959). Inoue et al. (1992) gave a transformation kinetic dependent on temperature and on $J_{2}$ stress invariant. Some models of transformation kinetics give the volume fraction rate of martensite as a function of the plastic strain rate. Olson and Cohen (1975) proposed a metallurgical strain induced transformation kinetic depending on shear band intersections within the austenitic phase. This model was later improved in order to take into account stress effects via triaxiality dependence (Stringfellow et al., 1992; Iwamoto et al., 1998), strain rate effects (Tomita and Iwamoto, 1995) and grain size effects (Iwamoto and Tsuta, 2000). Thermodynamical models based on the determination of the dissipation due to martensitic transformation enable to calculate the driving force for martensitic transformation (Fischer, 1997; Cherkaoui et al., 1998; Levitas, 1998). The latter approach takes into account plastic dissipation and the thermomechanical dependance of martensitic transformation.

Besides transformation kinetics, heuristic formulations of the transformation plasticity (Giusti, 1981) express the global transformation strain rate $\dot{\sim}_{\sim}^{T}$ as a function of the stress deviator $S$ :

$$
\dot{\sim}^{T}=K \cdot \Phi(f) \underset{\sim}{S} \dot{f}
$$

where $K$ is a constant and $\Phi$ a function of the martensitic volume fraction $f$.

Leblond et al. (1989,) developed a more complex mathematical formulation of the transformation strain extended by Taleb and Sidoroff (2003) and implemented in Castem finite element code. Fischer (1997) proposed a simple form of the transformation plasticity that has been extended to anisotropic materials by Fischer and Schlögl (1995). From a more mechanical point of view, Videau et al. (1994) and Azzouz et al. (2000) proposed a transformation function introducing a kinematical hardening due to martensitic transformation. Mahnken et al. (2009) presented a viscoplastic model with TRIP effect as modelled by Leblond (1989) implemented in Abaqus employing a homogenisation technique via a finite element unit cell.

Diani et al. (1995) considered a two-phase material (residual austenite and martensite) and proposed a uniaxial formulation of the transformation strain rate based on a self-consistent multiscale approach where a given transformation strain $\bar{\varepsilon}^{B}$ is considered as an eigenstrain within the forming martensite leading to the simple expression:

$$
\dot{E}_{x x}^{T}=\frac{5 \mu_{m}}{3 \mu_{e}+2 \mu_{m}} \dot{f} \bar{\varepsilon}_{x x}^{B}
$$

$\mu_{e}$ and $\mu_{m}$ being respectively the shear modulus of the homogenized material and of martensite.

With the expression of transformation plasticity and kinetics, Stringfellow et al. (1992) proposed an expression of the global mechanical behavior. Iwamoto and Tsuta (2000) used a yield function depending on the second and third invariant $J_{2}, J_{3}$ as proposed by Miller and McDowell (1996). Diani et al. (1995) used the description based on Eq. (2) to predict the uniaxial stress response of metastable austenite. This model reproduces the dynamic softening phenomenon where the global behavior is softer than the austenitic behavior when martensitic is created, as described by Olson and Cohen (1982). Hansel et al. (1998) proposed a hardening model based on a mixture law, that was implemented in a finite element code by Hilding and Schedin (2003) and applied to metal forming. Meftah et al. (2007) extended the finite element model of Ganghoffer and Simonsson (1998) at the scale of a martensitic plate to predict transformation plasticity and to study its interaction with classical plasticity in 16MND5 steel. Lani et al. (2002) also used finite element techniques in order to simulate the local nucleation of martensite platelets in an austenitic matrix according to the transformation criterion developed by Fischer (1997). Serri et al. (2005) implemented the model of Stringfellow et al. (1992) with the triaxiality dependency given by Iwamoto et al. (1998) in the finite element code Abaqus. A large strain formulation of transformation plasticity was proposed by Hallberg and Håkansson (2007) and compared to a standard plasticity model in the case of the deep drawing of a cup. More recently, Delannay et al. (2008) proposed an incremental mean-field homogenization approach to predict the behavior of multiphased TRIP steels along different loading paths and applied to the finite element study of the necking of a bar under uniaxial tension. Kouznetsova and Geers (2008) and Tjahjanto et al. (2007) implemented crystallographic transformation models in a finite element code to predict the behavior of a multicrystal with TRIP effect.

The present work addresses the presentation of a framework for a mean-field model of TRIP steels with a reduced number of internal variables compared to crystalline approach. The aim is the development of a semi-phenomenological thermomechanical model applied to metal forming of TRIP steels determining:

- the amount of mean transformation strain $\bar{\varepsilon}^{T}$ over all the martensitic variants and the evolution of martensitic transformation as function of control variables $\Sigma$ the overall stress state, $T$ the temperature expressed in a rate form:

$$
\dot{f}=() \underset{\sim}{\dot{\Sigma}}+() \dot{T}
$$

- the overall behavior, stress rate $\underset{\sim}{\dot{\Sigma}}$ as a function of $\underset{\sim}{\dot{E}}, \dot{T}, \dot{f}$ in the form: 


$$
\underset{\sim}{\dot{\Sigma}}=() \underset{\sim}{\dot{E}}+() \dot{f}+() \dot{T}
$$

Within a thermodynamic framework and using micromechanical tools, the constitutive equations of a new model between a crystalline approach and a phenomenological one are derived.

Kinematics of martensitic transformation are presented in Section 2 for the local, crystalline and mean-field modelling representations. The concept of Mean Instantaneous Transformation Strain (MITS) is introduced for the mean-field approach. In Section 3, the driving force for martensitic transformation is derived. Using respectively standard material behaviors and the local stress dependance of the MITS, the representation of plastic flow and martensitic transformation is proposed in Section 4. The local behavior of each phase and the transformation kinetic are derived. In Section 5 , the constitutive equations are presented and implemented in a multiscale modelling approach using a self-consistent scheme. The complete thermomechanical model for TRIP steels is applied in Section 6 to the case of thermal cooling at constant stress level and to the simulation of multiaxial monotonic loadings. Simulations are compared to experimental data from literature.

\section{Kinematics of martensitic transformation and constitutive equations}

In this section, three descriptions of the kinematics are presented: local, crystalline and mean-field (Fig. 2). The constitutive equations and the kinematics of transformation are derived in order to describe the overall strain rate $\dot{E}$ of a representative volume element (RVE) of metastable austenite exhibiting martensitic phase transformation. The focus is made on the new semi-phenomenological model that is defined with respect to the crystalline approach. The presented framework uses a small strain framework.

\subsection{Local representation of the RVE}

At point $r$ of the microstructure, martensite is created via nucleation of new domains accompanied by an instantaneous transformation strain $\varepsilon^{T}(r)$. Before transformation occurs and after transformation, plastic flow may occur in austenite and martensite resulting from dislocation motion. In addition, the lattice is submitted to a reversible thermoelastic strain. The deformation and transformation mechanisms can be described locally if the strain field is known at each point $r$ of the microstructure. The total strain tensor is decomposed additively into an elastic, thermal, transformation and plastic strain component as follows:

$$
\underset{\sim}{\varepsilon}(r)={\underset{\sim}{\varepsilon}}^{e}(r)+{\underset{\sim}{\varepsilon}}^{t h}(r)+{\underset{\sim}{\varepsilon}}^{T p}(r)
$$

where the elastic strain is linked to the stress tensor via the local tensor of the elastic moduli $\underset{\sim}{c}$ :

$$
\underset{\sim}{\sigma}(r)=\underset{\approx}{c}(r):{\underset{\sim}{\varepsilon}}^{e}(r)
$$

the thermal strain is defined as a function of the change in temperature $\Delta T$ with the thermal dilatation tensor ${\underset{\sim}{\text { th }}}^{\text {: }}$

$$
\stackrel{\sim}{\varepsilon}^{\text {th }}(r)=\underset{\sim}{\alpha^{t h}}(r) \cdot \Delta T
$$

the inelastic local strain is defined as the sum of the local plastic and transformation strain fields:

$$
\varepsilon_{\sim}^{T p}(r)={\underset{\sim}{\mathcal{E}}}^{p}(r)+\underset{\sim}{\varepsilon^{T}}(r)
$$

Thus the total strain Eq. (5) is defined from Eqs. (6)-(8) by:

$$
\underset{\sim}{\varepsilon}(r)=\underset{\sim}{\mathcal{c}^{-1}}(r): \underset{\sim}{\sigma}(r)+{\underset{\sim}{\alpha}}^{\text {th }}(r) \cdot \Delta T+{\underset{\sim}{\varepsilon}}^{T}(r)+{\underset{\sim}{\varepsilon}}^{p}(r)
$$

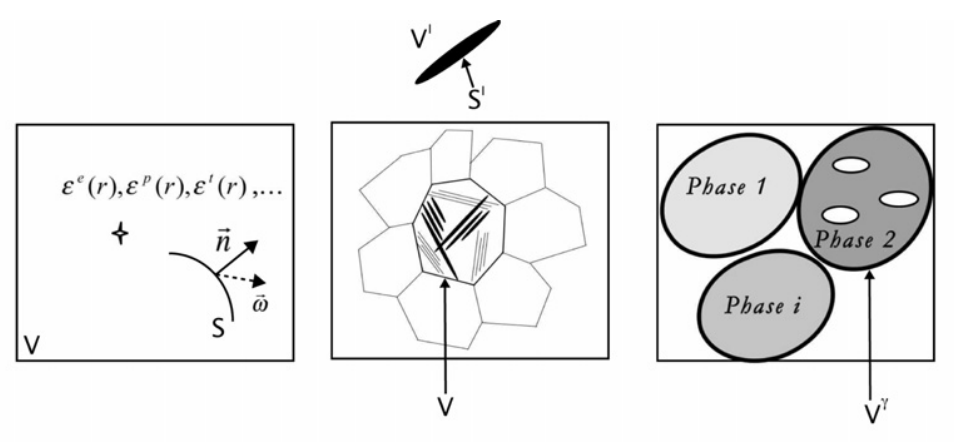

Fig. 2. Local, crystallographic and mean-field representations. 
The global strain state is defined by the boundary conditions and satisfies the compatibility equation $E=\operatorname{grad}^{s}(\underline{u})$ for a small strain formulation, where $\underline{u}$ is the displacement vector. For path dependent processes, a rate formulation is necessary. The global strain rate is additively decomposed in three parts respectively an elastic strain rate $\dot{E}^{e}$, a thermal strain rate $\dot{E}^{\text {th }}$ and an inelastic strain rate $\dot{E}^{T p}$ such as:

$$
\underset{\sim}{\dot{E}}=\underset{\approx}{C^{-1}}: \underset{\sim}{\dot{\Sigma}}+\alpha_{\sim}^{\text {th }} \cdot \dot{T}+\dot{\sim}^{T p}
$$

where $C$ is the global tensor of elastic moduli of the RVE and $\dot{\Sigma}$ the macroscopic stress rate.

The $\tilde{\tilde{m}}$ ean value of the inelastic strain rate is decomposed in a plastic strain rate $\dot{\sim}^{p}$ and a transformation strain rate $\dot{\sim}^{T}$ and is defined as:

$$
\dot{\sim}_{\sim}^{T p}=\dot{\sim}^{p}+{\underset{\sim}{\dot{E}}}^{T}=\frac{d}{d t}\left(\frac{1}{V}\right) \int_{V} \varepsilon_{\sim}^{T p}(r) d V+\frac{1}{V} \frac{d}{d t}\left(\int_{V}{\underset{\sim}{\sim}}^{T p}(r) d V\right)
$$

By neglecting the relative volume variation between austenite and martensite in Eq. (11), it reduces to:

$$
\dot{\sim}_{\sim}^{T p}=\frac{1}{V} \frac{d}{d t}\left(\int_{V} \varepsilon^{T p}(r) d V\right)
$$

Martensitic transformation is assumed to result from the nucleation and instantaneous growth of new martensitic domains creating boundaries between austenite and martensite. For the derivation of Eq. (12), the moving boundaries concept developed by Sabar and Berveiller (1991) equivalent to Reynolds transport theorem in fluid mechanics (Reynolds, 1903) is used, leading to the expression:

$$
\dot{\dot{E}}^{T p}=\frac{1}{V} \int_{V} \frac{d}{d t} \varepsilon^{T p}(r) d V-\frac{1}{V} \int_{S}\left[\varepsilon_{\sim}^{T p}\right] \underline{\omega} \cdot \underline{n} d S=\frac{1}{V} \int_{V}\left(\frac{d}{d t} \varepsilon^{T p}(r)-\left[\varepsilon_{\sim}^{T p}\right] \underline{\omega} \cdot \underline{n} \delta(S)\right) d V
$$

where $\left[\varepsilon^{T p}\right]=\varepsilon^{T p+}-\varepsilon^{T p-}$ is the jump of the inelastic strain across the moving boundary $S$ with velocity $\underline{\omega}$ and surface normal $\underline{n}$ (Fig. 3 ). The superscripts + and - are respectively for austenite and martensite.

$\delta(S)$ is the Dirac distribution over the surface $S$.

From the decomposition of $\varepsilon^{T p}$ into plastic and transformation parts (Eq. (8)), the jump can be expressed such as:

$$
\left[\varepsilon_{\sim}^{T p}\right]=\varepsilon_{\sim}^{p A}\left(r^{+}\right)-\left(\varepsilon_{\sim}^{p M}\left(r^{-}\right)+\varepsilon_{\sim}^{T}\right)
$$

With the assumption that the created martensite inherits from the plastic strain state in austenite previous to transformation, it follows that:

$$
\stackrel{\sim}{\varepsilon}^{p A}\left(r^{+}\right)={\underset{\sim}{\varepsilon}}^{p M}\left(r^{-}\right)
$$

Thus, the jump of the inelastic strain across the boundary $S$ is reduced to:

$$
\left[\varepsilon_{\sim}^{T p}\right]=-\mathcal{\sim}^{T}
$$

Since the growth of martensitic domains is instantaneous $\left(\frac{d}{d t} \varepsilon^{T}=0\right)$, the total inelastic strain rate expressed in Eq. (13) is finally reduced to:

$$
\dot{\sim}_{\sim}^{T p}=\frac{1}{V} \int_{V} \frac{d}{d t} \varepsilon^{p}(r) d V+\frac{1}{V} \int_{V} \varepsilon_{\sim}^{T} \underline{\omega} \cdot \underline{n} \delta(S) d V
$$

the local transformation strain rate being defined from Eq. (17) as:

$$
\dot{\tilde{\varepsilon}}^{T}=\varepsilon_{\sim}^{T} \underline{\omega} \cdot \underline{n} \delta(S)
$$

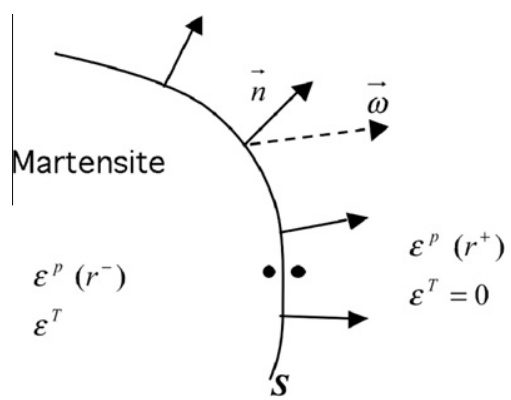

Fig. 3. Moving boundary between austenite (+) and martensite (-). 


\subsection{Crystalline representation}

A polycrystal is characterized by the crystalline structure of each crystal (ferrite, austenite, bainite) and their crystallographic orientation distribution (texture) with respect to a global reference (rolling direction, testing direction). This approach is based on a description in each single crystal of volume $V$ (Fig. 2). For TRIP steels, the presented model has been developed by Cherkaoui et al. (2000) and extended to the determination of transformation texture by Kubler et al. (2003).

The essential microscale mechanisms are:

- martensitic transformation, where the inelastic transformation strain field is discretised over 24 variants $I$ of volume $V^{I}$ described by their habit plane and transformation direction. Thus, the transformation strain field is a non-continuous field, equal to zero in austenite $(A)$ and to a discrete value $\varepsilon^{T_{I}}$ in each single martensite variant $I$. $\varepsilon^{T_{I}}$ is assumed uniform over $V^{I}$. It is a material data calculated using the Wechsler-Liebermann-Read theory (see Wechsler et al., 1953). This latter theory needs the knowledge of the accommodating strain mechanisms and of the Bain's strain. The transformation strain at a point $r$ inside a crystal is expressed as:

$$
\varepsilon_{\sim}^{T}(r)={\underset{\sim}{\varepsilon}}^{T_{I}} H^{I}(r)
$$

with the Heavyside function defined as:

$$
H^{I}(r)= \begin{cases}1 & \text { if } r \in V^{I}, \\ 0 & \text { if } r \notin V^{I}\end{cases}
$$

In the crystallographic representation, the transformation strain rate over the variants is derived from Eq. (18) by:

$$
\dot{\dot{\varepsilon}}^{T}=\sum_{I} \underline{\varepsilon}^{\varepsilon^{T}} \underline{\omega}^{I} \cdot \underline{n}^{I} \delta\left(S^{I}\right)
$$

and the mean transformation strain rate in the single crystal is:

$$
\dot{\bar{\varepsilon}}_{\sim}^{T}=\frac{1}{V} \int_{V} \sum_{I} \underline{\sim}_{\sim}^{T_{I}} \underline{\omega}^{I} \cdot \underline{n}^{I} \delta\left(S^{I}\right) d V=\sum_{I} \dot{f}^{I} \underline{\sim}^{T_{I}}
$$

where $\dot{f}^{I}$ is the volume fraction rate of variant $I$ representing the volume $\dot{V}^{I}$ swept by the moving surfaces $S^{I}$ of the RVE during the martensitic transformation and is defined from Eq. (22) as:

$$
\dot{f}^{I}=\frac{1}{V} \int_{V} \underline{\omega}^{I} \cdot \underline{n}^{I} \delta\left(S^{I}\right) d V=\frac{1}{V} \int_{S} \underline{\omega}^{I} \cdot \underline{n}^{I} d S=\frac{\dot{V}^{I}}{V}
$$

- the plastic flows of parent $(A)$ and product phases $(M)$ contributing to the total plastic strain rate in the single crystal such as:

$$
\frac{1}{V} \int_{V} \dot{\dot{\varepsilon}}^{p}(r) d V=(1-f) \dot{\sim}^{p A}+f \dot{\sim}^{p M}
$$

Crystallographic representation of plastic flow are used where the plastic strain field results from the sum of discrete slips $\gamma$ on slip systems $g$ defined by their crystalline orientation with respect to the global reference. The plastic strain is defined as:

$$
\dot{\dot{\varepsilon}}^{p}=R_{\sim}^{g} \dot{\gamma}^{g}
$$

where $R_{\sim}^{g}$ is the orientation tensor (Schmid tensor) of the slip system g. Using Eq. (25), relation (24) is expressed as:

$$
(1-f) \sum_{h} R_{\sim}^{h A} \dot{\gamma}^{h A}+\sum_{I}\left[f^{I} \sum_{g} R_{\sim}^{g l} \dot{\gamma}^{g I}\right]
$$

The total inelastic strain rate of a single crystal of austenite transforming into martensite, is derived adding Eqs. (26) and (22):

$$
\stackrel{\sim}{\dot{E}}^{T p}=(1-f) \sum_{h} R_{\sim}^{h A} \dot{\gamma}^{h A}+\sum_{I}\left[f^{I} \sum_{g} R_{\sim}^{g I} \dot{\gamma}^{g l}\right]+\sum_{I} \dot{f}^{I} \dot{\varepsilon}^{T_{I}}
$$

From relation (27), the internal variables for the crystallographic representation are defined by:

- the plastic slip on each crystallographic slip system in each phase, 
- the volume fraction of each martensite variant.

This type of representation allows to take into account crystallographic textures and their evolution during metal forming (Kubler et al., 2003; Petit et al., 2007) for each family of grains. Nevertheless, the number of internal variables is important (48 for plastic flow, 24 for martensitic transformation). In order to further reduce the number of the internal variables, a mean-field model more suitable for finite element simulation of macroscopic process, is proposed in next sections.

\subsection{Mean field representation}

In the mean-field representation, the crystallographic mechanisms are not individually described. Only the average behavior of each phase is modeled using generalized standard material laws for the description of plastic flow. At a current stage of the thermomechanical loading, the RVE which is initially the austenitic volume $V^{\prime}$ is divided into two domains (Fig. 4):

- an austenitic phase $(A)$ of volume fraction $(1-f)=V^{A} / V^{\prime}$. It is assumed to be composed of the residual not transformed austenite and of the martensitic domains in nucleation at time $t$. The transformation of those martensitic domains is defined by an infinitesimal volume fraction $d f=\dot{f} d t$ with respect to the volume $V$ ", and is accompanied by an "eigenstrain" $\bar{\xi}^{T}$ defined as a Mean Instantaneous Transformation Strain (MITS).

- an alreãdy created martensitic domain $(M)$ including the already formed martensitic variants. Its volume fraction is $f=V^{M} / V^{\gamma}$

Since the martensitic domain in formation includes all the variants transforming at the same time, the MITS is defined as the global contribution of the transformation strain of each individual variant. The MITS encompasses, at the same time, the Bain strain and the lattice invariant strain (plastic slip, twinning) necessary to accommodate the incompatible Bain strain. Thus, a part of the Greenwood-Johnson effect is captured by the MITS. The mean transformation strain rate over the austenitic phase is defined by comparison to the crystallographic representation (Eq. (22)):

$$
\underset{\sim}{\dot{\mathcal{\varepsilon}}^{T}}=\underset{\sim}{\bar{\xi}^{T}} \dot{f}=\frac{1}{V} \int_{S}{\underset{\sim}{\mathcal{\varepsilon}}}^{T} \underline{\omega} \cdot \underline{n} d S=\sum_{I} \underline{\sim}^{T_{I}} \dot{f}^{I}
$$

From Eq. (28), the MITS is expressed as:

$$
\underset{\sim}{\bar{\xi}^{T}}=\frac{\sum_{I} \varepsilon_{\sim}^{T_{I}} \dot{f}^{I}}{\dot{f}}
$$

In this new relation (29), it is important to note that the Magee effect, i.e. the selection of each martensitic variant by the local stress, has to be implicitly taken into account in the expression of the MITS. Unlike the crystallographic representation, the mean-field representation does not take into account the morphology and the selection of individual martensitic variants according to their crystallographic orientation.

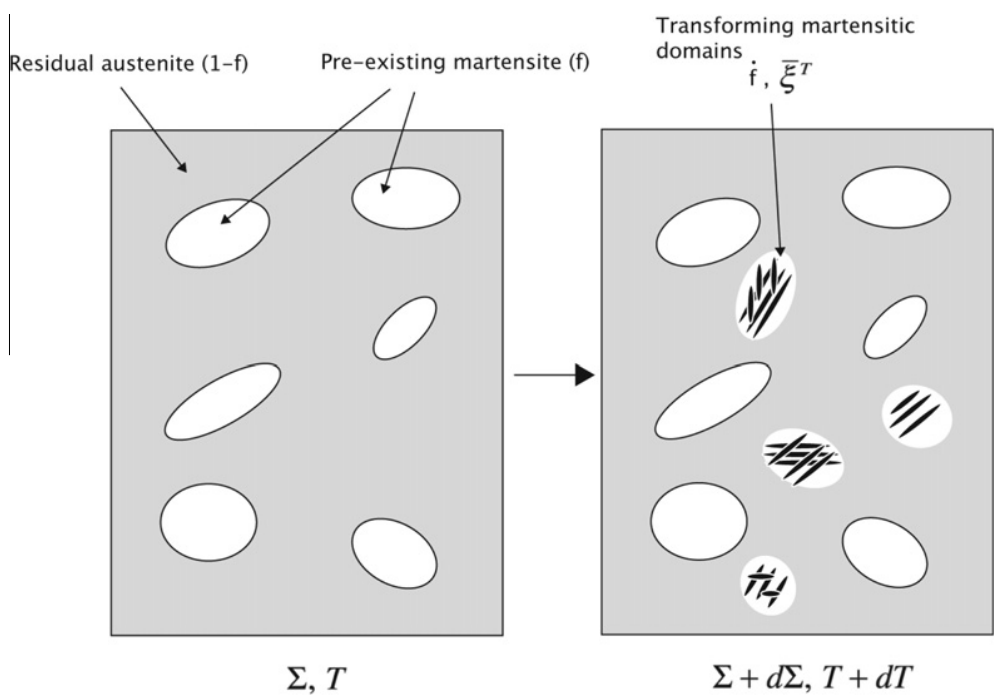

Fig. 4. Transformation of martensitic domains of volume fraction $\dot{f}$ accompanied by the mean instantaneous transformation strain (MITS). 
However, the "orientation effect" of the transformation strain is kept by choosing the MITS to be dependent on stress level in austenite. The representation of the MITS is addressed in Section 4.2.

Diani et al. (1995) noticed that the mean transformation strain rate $\bar{\varepsilon}^{T}$ is, in general, not equal to the experimentally measured macroscopic transformation strain rate $\dot{E}^{T}$. Although both quantities take into account the plastic accommodation in the martensite domains (a part of Greenwood Johnson effect), another plastic accommodation in the "soft" phase (austenite) resulting from the incompatibility of the transformation strain generating internal stress distribution must exist. This is the second part of the Greenwood Johnson effect. The TRIP effect can be defined, according to Diani et al. (1995) as:

$$
\dot{\mathrm{E}}^{T} \neq{\underset{\sim}{\dot{\varepsilon}}}^{T}
$$

This effect is captured by the micromechanical equations presented in Section 5 .

In addition to the transformation strain, the thermal $\varepsilon^{\text {th }}$ and mean elastoplastic strains $\varepsilon^{e p}$ of each phase are described in Section 4.1. For a thermomechanical behavior with phase transformation represented by the MITS (Eq. (29)) and a global transformation rate $\dot{f}$, the mean-field representation allows to decompose the global strain rate as:

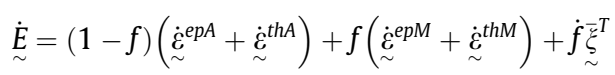

or also as:

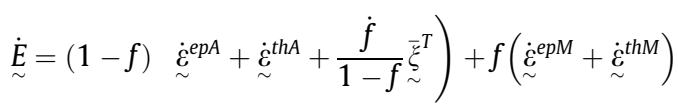

The number of internal variables of the mean-field representation is reduced to:

- the average volume fraction of martensite $f$,

- the MITS tensor $\bar{\xi}^{T}$.

- the average elastoplastic strain in each phase $\varepsilon^{e p}$.

For multiphase steel grades containing ferrite $(\alpha)$, bainite $(b)$ and metastable austenite $(\gamma)$ of respective volume fractions $F^{\alpha}, F^{b}$ and $F^{\gamma}$, the extension is straightforward and the total strain rate is divided in each phase such as:

$$
\underset{\sim}{\dot{E}}=F^{\alpha}{\underset{\sim}{\dot{\varepsilon}}}^{\alpha}+F^{b} \underset{\sim}{\dot{\varepsilon}^{b}}+F^{\gamma}{\underset{\sim}{\dot{\varepsilon}}}^{\gamma}
$$

with

$$
F^{\alpha}+F^{b}+F^{\gamma}=1
$$

By taking into account the thermoelastoplastic behaviors of ferrite, bainite and the behavior of metastable austenite derived in Eq. (32), the total strain rate of a multiphased TRIP steel (Eq. (33)) is:

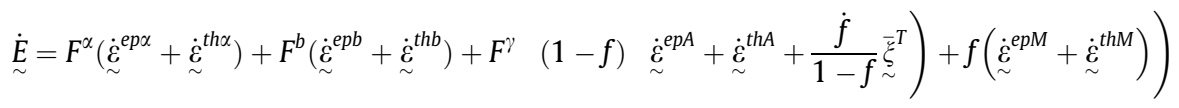

The reduced number of internal variables compared to the crystallographic representation is beneficial for metal forming simulations that require a limited computational time to be effective.

Expression (32) shows that the unstable austenitic phase in TRIP steels can be treated as a non-linear composite with an evolving volume fraction of martensite accompanied by a transformation strain (i.e. the MITS) exhibited by the austenite to martensite phase transformation.

In the mean-field representation, it is important to note that the MITS is not a material property, unlike in the crystallographic representation, but an "average" tensor regrouping the contributions of each variant that is nucleated at the same time at different locations of the RVE, as seen in Fig. 4. Hence, the MITS depends strongly on the local stress state in austenite. In order to determine the evolution of the martensite volume fraction $\dot{f}$, a thermodynamic framework is presented in Section 3 applied to the local, crystalline and mean-field representations. The behavior laws for the MITS and for plastic flow in each phase are discussed in Section 4.

\section{Thermodynamics and driving forces for martensitic transformation}

The description of martensitic transformation in steels (Cherkaoui et al., 1998) or in shape memory alloys (Patoor and Berveiller, 1997) may be considered as thermodynamical irreversible processes. It is based on the calculation of the intrinsic dissipation $D$ which is defined, in the quasi-static and isothermal assumption, by:

$$
D=P_{\text {ext }}-\dot{\Phi}
$$

where $P_{\text {ext }}$ is the power of external forces and $\dot{\Phi}$ the variation of Helmholtz free energy $\Phi$. 
The Helmholtz free energy $\Phi$ is composed of:

- the elastic strain energy $W^{e}$ of density $w^{e}=\frac{1}{2} \sigma: \varepsilon^{e}$,

- the crystallographic energy (chemical energy) $\Phi^{\text {chem }}$ of density $\phi^{\text {chem }}$

- the interface energy of all phases, usually neglected in comparison with $W^{e}$ and $\Phi^{\text {chem }}$

In case of a quasi-static and isothermal process, Helmholtz free energy of the RVE with volume $V$ is:

$$
\Phi=W^{e}+\Phi^{\text {chem }}=\frac{1}{2 V} \int_{V} \underset{\sim}{\sigma}: \underset{\sim}{\varepsilon^{e}} d V+\frac{1}{V} \int_{V} \phi^{\text {chem }} d V
$$

Considering the concept of moving boundaries of normal velocity $\underline{\omega} \cdot \underline{n}$, the variation of Helmholtz free energy $\dot{\Phi}$ is obtained as the time derivative of Eq. (37) such as:

$$
\dot{\Phi}=\frac{1}{V} \int_{V}\left(\dot{w}^{e}(r)+\dot{\phi}^{\text {chem }}(r)\right) d V+\frac{1}{V} \int_{S}\left(\left[w^{e}(r)\right]+\left[\phi^{\text {chem }}(r)\right]\right) \underline{\omega} \cdot \underline{n} d S
$$

where $[X]$ is the jump of quantity $X$ across the moving boundaries.

In the present case, the chemical energy does not change according to the load (i.e. $\dot{\phi}^{\text {chem }}=0$ ), so the first term of Eq. (38) is written as:

$$
\frac{1}{V} \int_{V}\left(\dot{w}^{e}(r)+\dot{\phi}^{\text {chem }}(r)\right) d V=\frac{1}{V} \int_{V} \underset{\sim}{\sigma}:\left(\underset{\sim}{\dot{\varepsilon}}-{\underset{\sim}{\dot{\varepsilon}}}^{T p}\right) d V
$$

where $\dot{\varepsilon}^{T p}$ is the inelastic strain rate.

Close to the equilibrium temperature $T_{0}$, the difference of chemical energies between austenite and martensite may be expressed by a linear relation with respect to the temperature $T$ :

$$
\left[\phi^{\text {chem }}(r)\right]=\phi^{\text {chem } M}-\phi^{\text {chemA }}=B\left(T-T_{0}\right)
$$

where $B$ and $T_{0}$ are material parameters depending on the chemical composition. At cooling at $T=M_{S}$, martensite is created without any mechanical stress.

The jump of elastic strain energy across the moving boundary is:

$$
\left[w^{e}(r)\right]=\frac{1}{2}\left(\sigma_{\sim}^{A}\left(r^{+}\right):\left(\sim_{\sim}^{A}\left(r^{+}\right)-{\underset{\sim}{\varepsilon}}^{T p A}\left(r^{+}\right)\right)-{\underset{\sim}{\sigma}}^{M}\left(r^{-}\right):\left({\underset{\sim}{\varepsilon}}^{M}\left(r^{-}\right)-{\underset{\sim}{\varepsilon}}^{T p M}\left(r^{-}\right)\right)\right)
$$

In the case of uniform elasticity, Cherkaoui et al. (1998) express the variation of Helmholtz free energy from Eqs. (39)-(41) as:

$$
\dot{\Phi}=\frac{1}{V} \int_{V} \underset{\sim}{\sigma}:\left(\underset{\sim}{\dot{\varepsilon}}-{\underset{\sim}{\dot{\varepsilon}}}^{T p}\right) d V-\frac{1}{V} \int_{S}\left(\frac{1}{2}\left({\underset{\sim}{\sigma}}^{A}\left(r^{+}\right)+{\underset{\sim}{\sigma}}^{M}\left(r^{-}\right)\right):\left[\underset{\sim}{\varepsilon}(r)-{\underset{\sim}{\varepsilon}}^{T p}(r)\right]-B\left(T-T_{0}\right)\right) \underline{\omega} \cdot \underline{n} d S
$$

where $\sigma^{A}\left(r^{+}\right)$and $\sigma^{M}\left(r^{+}\right)$are the stress tensors on each side of the moving boundary.

The power of external forces resulting from an applied load on the surface of a volume $V$, is defined by:

$$
P_{\text {ext }}=\frac{1}{V} \int_{\partial V}(\underset{\sim}{\sigma} \cdot \underline{n}) \cdot \underline{v} d S
$$

where $\underline{v}$ is the particle velocity on the boundary $\partial V$ with normal vector $\underline{n}$.

Using the divergence theorem, Eq. (43) can be written as:

$$
P_{e x t}=\frac{1}{V} \int_{V} \operatorname{div}(\underset{\sim}{\sigma} \cdot \underline{v}) d V+\frac{1}{V} \int_{S}[(\underset{\sim}{\sigma} \cdot \underline{n}) \cdot \underline{v}] d S
$$

The calculation of the power of external forces uses Hadamard relation (Hadamard, 1903) between the jump of the velocity, the displacement gradient and the normal velocity $\underline{\omega} \cdot \underline{n}$ of the moving boundary $S$ :

$$
[\underline{v}]=-[\underset{\sim}{\operatorname{grad}}(\underline{u})] \cdot \underline{n}(\underline{\omega} \cdot \underline{n})
$$

Since the traction vector and the displacement are continuous along the boundary $S([\sigma] \cdot \underline{n}=0,[u]=0)$, the expression of $P_{\text {ext }}$ is reduced to:

$$
P_{e x t}=\frac{1}{V} \int_{V} \underset{\sim}{\sigma}: \underset{\sim}{\dot{\varepsilon}} d V-\frac{1}{2 V} \int_{S}\left({\underset{\sim}{\sigma}}^{A}\left(r^{+}\right)+\underset{\sim}{\sigma^{M}}\left(r^{-}\right)\right):[\underset{\sim}{\varepsilon}(r)] \underline{\omega} \cdot \underline{n} d S
$$

The global dissipation is obtained by calculating $D=P_{\text {ext }}-\dot{\Phi}$

$$
D=\frac{1}{V} \int_{V} \underset{\sim}{\sigma}: \dot{\sim}^{T p} d V-\frac{1}{V} \int_{S}\left(\frac{1}{2}\left(\sigma_{\sim}^{A}\left(r^{+}\right)+\sigma_{\sim}^{M}\left(r^{-}\right)\right):\left[\underline{\varepsilon}^{T p}(r)\right]+B\left(T-T_{0}\right)\right) \underline{\omega} \cdot \underline{n} d S
$$


The dissipation is decomposed in two contributions:

$$
D=D_{V}+D_{S}
$$

$D_{V}$ being the volumic dissipation accounting for the evolution of the plastic strain field (transformation is not included)

$$
D_{V}=\frac{1}{V} \int_{V} \underset{\sim}{\sigma}: \dot{\sim}_{\sim}^{T p} d V
$$

and $D_{S}$ corresponding to the dissipation due to moving boundaries $S$

$$
D_{S}=-\frac{1}{V} \int_{S}\left(\frac{1}{2}\left(\sigma_{\sim}^{A}\left(r^{+}\right)+\sigma_{\sim}^{M}\left(r^{-}\right)\right):\left[\mathcal{\varepsilon}^{T p}(r)\right]+B\left(T-T_{0}\right)\right) \underline{\omega} \cdot \underline{n} d S
$$

Assuming the inheritage of plastic strain when martensite is formed (i.e. identical plastic strain on both side of the boundary, see Eq. (16)), the jump of the inelastic strain is:

$$
\left[\varepsilon_{\sim}^{T p}\right]=-{\underset{\sim}{\varepsilon}}^{T}
$$

From the dissipation expressions, the driving forces $\left(F_{p}, F_{f}\right)$ of the flux $\dot{X}$ can be calculated for both mechanisms (i.e. plastic flow and martensitic transformation):

$$
D=F \cdot \dot{X}
$$

For the crystallographic representation where $\varepsilon^{T}=\varepsilon^{T_{I}}$, the Kroner and Mori-Tanaka methods (Kröner, 1961; Mori and Tanaka, 1973) are used to determine the stress in martensite variant $I$ as:

$$
\sigma_{\sim}^{M}\left(r^{-}\right)=\sigma_{\sim}^{A}\left(r^{+}\right)+\underset{\approx}{C}:(\underset{\approx}{I}-\underset{\approx}{S}):\left({\underset{\sim}{\tau}}^{T p_{A}}-{\underset{\sim}{\varepsilon}}^{T p_{I}}\right)
$$

According to the kinematical study, the inelastic strain in austenite is reduced to its plastic part and the inelastic strain in martensite is reduced to the sum of transformation and plastic strains. Assuming that the plastic strain in martensite is inherited from the parent austenitic phase, the relation (53) becomes:

$$
{\underset{\sim}{\sim}}^{M}\left(r^{-}\right)=\underset{\sim}{\sigma^{A}}\left(r^{+}\right)-\underset{\approx}{C}:(\underset{\approx}{I}-\underset{\approx}{S}):{\underset{\sim}{\sim}}^{T_{I}}
$$

Thus, in the assumption of an homothetic and instantaneous growth of martensitic platelets, the authors express the dissipation (50) associated to the nucleation of a martensitic variant as:

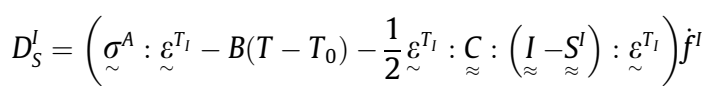

where $\sigma^{A}$ is the mean stress in austenite over a crystal, $C$ the elasticity compliance tensor and $S^{I}$ the Eshelby tensor of variant $I$. So the term $-\frac{1}{2} \varepsilon_{\sim}^{T_{I}}: C:\left(\underset{\widetilde{N}}{S_{\tilde{S}}}\right): \varepsilon_{\sim}^{T_{I}}$ represents the self-ĩnduced contribution of the variant on its associated driving force. In this representation, it represênts a constant for each variant.

With a similar approach, the dissipation due to the formation of the average domains of martensite, where $\varepsilon_{\sim}^{T}=\bar{\xi}^{T}$, can be written as:

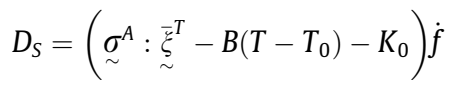

where $\sigma^{A}$ is the mean stress over the austenitic phase and $K_{0}$ represents the accommodation of the MITS and, by comparison to the crystalline representation, it is expressed as $\left.\frac{1}{2}{\underset{\xi}{T}}^{T} \underset{\sim}{C}: \underset{\sim}{I}-\underset{\sim}{S}\right): \underbrace{T}$. In this case, the Eshelby tensor is assumed for spherical domains of nucleated martensite.

The term $K_{0}$ should depend on the MITS tensor, and consequently on the volume fraction of martensite $f$ and on the plastic strain state in austenite $\varepsilon^{p A}$. Its value will affect the transformation criterion through the critical driving force and its derivative contributes in the determination of the rate of martensite volume fraction. For the sake of simplicity, it is assumed to be constant and that the hardening effect of the already formed volume fraction of martensite and the effect of plastic strain in austenite is captured through critical driving forces $K^{f}$ and $K^{p}$. The phenomenological expressions of $K^{f}$ and $K^{p}$ are discussed in Section 4.3.

Using Eq. (52), the driving force acting on martensite transformation can be identified for each representation from Eqs. (55) and (56):

- crystallographic representation with instantaneous formation of martensitic variants $I$ :

$$
\left.F_{f}^{I}=\sigma_{\sim}^{A}: \varepsilon_{\sim}^{T_{I}}-B\left(T-T_{0}\right)-\frac{1}{2} \varepsilon_{\sim}^{T_{I}}: \underset{\approx}{C}: \underset{\approx}{(I}-\underset{\approx}{S}\right): \varepsilon_{\sim}^{T_{I}}
$$

- mean-field representation with formation of martensitic domains accompanied by the MITS: 


$$
F_{f}=\underset{\sim}{\sigma^{A}}: \underset{\sim}{\bar{\xi}^{T}}-B\left(T-T_{0}\right)-K_{0}
$$

In the three representations, the driving forces depend on the stress and temperature state in austenite. In case of an uniform stress state, i.e. $\underset{\sim}{\Sigma}=\frac{1}{2}\left(\sigma_{\sim}^{A}\left(r^{+}\right)+\sigma_{\sim}^{M}\left(r^{-}\right)\right)$, Eq. (55) is simplified to the expression:

$$
D_{S}=\sum_{I}\left(\sum_{\sim}:{\underset{\sim}{\varepsilon^{T}}}^{T_{I}}-B\left(T-T_{0}\right)\right) \dot{f}^{I}
$$

This is the expression of Patel and Cohen criterion (Patel and Cohen, 1953) for a multiaxial stress state. As modelled in crystalline plasticity, $\underset{\sim}{\Sigma}: \varepsilon_{\widetilde{T}}^{T_{I}}$ represents the resolved stress on variant $I$, i.e. the projection of the macroscopic stress tensor $\Sigma$ on the normal of the habit plane and on the transformation direction.

By inserting in Eq. (59) the definition of MITS (Eq. (29)) and considering that $\sum_{l} \dot{f}^{I}=\dot{f}$, the dissipation for the mean-field representation is simplified to:

$$
D_{S}=\left(\sum_{\sim}: \bar{\sim}^{T}-B\left(T-T_{0}\right)\right) \dot{f}
$$

\section{Behavior laws for elementary processes}

A volume of material is submitted to global control variables such as the strain increment $d E=\dot{E} d t$, an increment of martensite volume fraction within the austenitic volume $d f=\dot{f} d t$ and a temperature change $d T=\tilde{T} d t$. An uniform temperature $T$ is assumed. The representative volume element (RVE) is composed of metastable austenite that transforms to martensite under thermomechanical loading. The total strain rate $\dot{E}$ has been derived in Eq. (32). With respect to the volume fraction defined in the mean-field approach (Section 2.3), the total strain rates in the transforming austenitic phase $(A)$ and in the already transformed martensite $(M)$ in Eq. (32) are given by

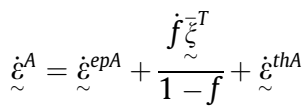

$$
\begin{aligned}
& \dot{\sim}^{M}=\dot{\sim}^{e p M}+\dot{\sim}^{t h M}
\end{aligned}
$$

In order to derive the stress rate in each phase, needed for example in the expression of the driving force of the mean-field model (Eq. (58)), the behavior law of each phase is defined with the elastoplastic tangent modulus $\underset{\sim}{l^{e p}}$ by

$$
\underset{\sim}{\dot{\sigma}}=\underset{\approx}{l^{e p}}:{\underset{\sim}{\dot{\varepsilon}}}^{e p}
$$

Inserting Eqs. (61) and (62) in Eq. (63), a generic form of the behavior law is given by:

$$
\underset{\sim}{\dot{\sigma}}=\underset{\approx}{l e p}: \underset{\sim}{\dot{\varepsilon}}-\underset{\sim}{n} \cdot \dot{f}-\underset{\sim}{m} \cdot \dot{T}
$$

with $m$, the thermal modulus, such as:

$$
\underset{\sim}{m}=\underset{\approx}{l^{e p}}: \underset{\sim}{\alpha^{t h}}
$$

and $n$ a second order tensor associated to martensitic transformation defined in austenite and martensite as:

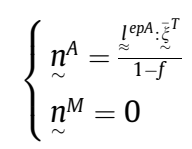

The driving parameters are the total strain in each phase, the temperature and the martensite volume fraction. The material properties are included in the expressions of $l^{e p}, n$ and $\underset{\sim}{m}$. In order to determine those expressions, modelling of plastic flow, the MITS behavior and of martensitic transformation is proposed. In the following subsections, the modelling of the evolution of the internal variables of the new mean-field model (i.e. plastic flow, MITS and martensitic volume fraction) is presented.

\subsection{Modelling plastic flow inside each phase}

Assuming isotropic behavior in each phase, plastic flow in the different phases is described with a standard approach using the phenomenological Von-Mises yield criterion. The elastic behavior is described through the shear modulus $\mu=80 \mathrm{GPa}$ and the Poisson ratio $v=0.3$. The yield surface is defined by the yield function $Y$ such as:

$$
Y=\sigma_{e q}-\sigma_{y}-R
$$


where $\sigma_{y}$ is the yield stress and the Von-Mises stress is given by

$$
\sigma_{e q}=\sqrt{\frac{3}{2}(\underset{\sim}{s}-\underset{\sim}{X}):(\underset{\sim}{s}-\underset{\sim}{X})}
$$

$R$ and $X$ representing the isotropic and the kinematical hardenings are functions of the plastic strain $\varepsilon^{p}$ and its equivalent value $\widetilde{\varepsilon_{e q}^{p}}$ such as:

$$
\begin{aligned}
& R=Q_{0}\left(1-e^{-b \cdot \varepsilon_{e q}^{p}}\right) \\
& \underset{\sim}{X}=G \cdot{\underset{\sim}{q}}^{p}
\end{aligned}
$$

where $Q_{0}, b$ and $G$ are material parameters.

Using the standard approach for associated plasticity (Lemaitre and Chaboche, 1985), the elastoplastic modulus of each phase is derived as a function of the hardening parameters:

$$
\underset{\approx}{l^{e p}}=\underset{\approx}{C}-\beta \frac{9 \mu^{2}}{(H+3 \mu) \sigma_{e q}^{2}}(\underset{\sim}{s}-\underset{\sim}{X}) \otimes(\underset{\sim}{s}-\underset{\sim}{X})
$$

where $\beta$ depends on the yield function:

$$
\begin{array}{ll}
\beta=1 & \text { if } Y=0 \\
\beta=0 & \text { if } Y<0
\end{array}
$$

with $C$ the tensor of elastic moduli, $\mu$ being the shear modulus, $\underset{\sim}{s}$ the stress deviator and $H$ defined as:

$$
H=\frac{\partial R}{\partial \varepsilon_{e q}^{p}}
$$

\subsection{Modelling the MITS}

The MITS $\bar{\xi}^{T}$ represents the mean contribution of transformation strain rate over all the activated variants of martensite. It is additively decomposed in a volumic part $\frac{1}{3} \theta \delta$ and a deviatoric strain contribution $e_{\sim}^{T}$ :

$$
\underset{\sim}{\bar{\xi}^{T}}=\frac{1}{3} \theta \underset{\sim}{\delta}+\underset{\sim}{e^{T}}
$$

with

$$
\theta=\frac{\Delta V}{V}=\bar{\xi}_{k k}^{T}
$$

being the isotropic volume variation, resulting from the crystallographic transformation from the austenitic to the martensitic lattice. $\theta$ is independent of the stress level and considered as a material data.

Due to its deviatoric nature, the transformation strain is a function of the local deviatoric stress in austenite $s^{A}=\sigma^{A}-\frac{1}{3} \operatorname{Tr}\left(\sigma^{A}\right) \delta$. In a stress free austenitic single crystal under cooling, all the martensitic variants are active leading to an instantaneoüs global transformation strain over the crystal equal to $\theta$. In the stress assisted transformation process, with the applied stress, only well oriented variants are active leading to an increased transformation strain in the direction of the applied stress. This instantaneous transformation strain reaches a maximum when only a single variant is selected according to its orientation with respect to the stress state.

In this work, in order to capture the saturation of the MITS with the local deviatoric stress, it is assumed that the deviatoric part of the MITS $\left(\mathcal{\sim}^{T}\right)$ is a quadratic non-linear function of the deviatoric stress in austenite $e^{T}\left(\mathcal{\sim}^{A}\right)$. Considering no preferential orientation when no stress is applied, the function has to verify $\underset{\sim}{e^{T}}(0)=0 . e_{\sim}^{T}$ can be written as:

$$
e_{i j}^{T}=\left(D_{i j k l}^{1}+\frac{1}{2} D_{i j k l m n}^{2} s_{m n}^{A}\right) s_{k l}^{A}
$$

$D_{\sim}^{1}$ and $D_{\widetilde{\sim}}^{2}$ are respectively fourth and sixth order constant tensors. For an isotropic representation, those tensors are defined with 5 parameters (2 for $D^{1}, 3$ for $D^{2}$ ) (Lubarda, 1999; Duda and Paszkiewicz, 1999). Using the deviatoric status of $e^{T}$ and $s^{A}$, there are two independent parameters. As calculated in Appendix B, the following expression is obtained:

$$
e_{i j}^{T}=d_{1}^{\prime} s_{i j}^{A}+d_{2}^{\prime}\left(\frac{9}{16}\left[s_{k l}^{A} s_{k l}^{A}\right] \delta_{i j}-\frac{27}{16} s_{k i}^{A} s_{k j}^{A}\right)
$$

Including volume variation, the MITS is derived from Eq. (77) by: 


$$
\bar{\xi}_{i j}^{T}=\frac{\theta}{3} \delta_{i j}+d_{1}^{\prime} s_{i j}^{A}+d_{2}^{\prime}\left(\frac{9}{16}\left[s_{k l}^{A} s_{k l}^{A}\right] \delta_{i j}-\frac{27}{16} s_{k i}^{A} s_{k j}^{A}\right)
$$

where $d_{1}^{\prime}\left(\mathrm{MPa}^{-1}\right)$ and $d_{2}^{\prime}\left(\mathrm{MPa}^{-2}\right)$ are two parameters.

For $d_{2}^{\prime}=0$, the expression of the MITS is similar to the one proposed by Leblond (1989). Fig. 5 shows the evolution of the MITS with respect to an applied tensile load. The sign of $d_{1}^{\prime}$ represents the variation of the MITS with the deviatoric part of the stress. If $d_{1}^{\prime}>0$, the MITS $\underset{\sim}{\xi^{T}}$ increases with $\underset{\sim}{s}$. According to the values taken by $d_{2}^{\prime}$, the non-linear evolution of the MITS with $S^{A}$ is emphasized.

\subsection{Martensite transformation modelling}

The classical methodology in irreversible processes consists in comparing the thermodynamic driving forces acting on the martensite volume fraction $f$ with the corresponding critical force. With the help of the consistency rule, the evolution of the volume fraction $f$ is obtained.

\subsubsection{Transformation criterion}

By combining the expression of the MITS (78) with the average stress tensor in austenite, the driving force $F_{f}$ for transformation is expressed with the three invariants $\left(I_{1}, J_{2}, J_{3}\right)$ of the average stress in austenite (see Appendix B) as:

$$
F_{f}=\underset{\sim}{\sigma^{A}}: \underset{\sim}{\xi^{T}}-B\left(T-T_{0}\right)-K_{0}=I_{1} \frac{\theta}{3}+2 d_{1}^{\prime} J_{2}-\frac{81}{16} d_{2}^{\prime} J_{3}-B\left(T-T_{0}\right)-K_{0}
$$

It is the invariant representation of the driving force for transformation in the sense of invariance with respect to the anisotropy of the internal microstructure of austenite. In the framework of time independent mechanisms, the evolution of martensitic volume fraction is derived by comparing the driving force $F_{f}$ to a critical force $F_{f}^{c}$. Thus the transformation criterion is written such as:

$$
\left\{\begin{array}{lll}
F_{f}<F_{f}^{c}, \quad \forall \dot{F}_{f} & & \dot{f}=0 \\
F_{f}=F_{f}^{c} & \text { and } \quad \dot{F}_{f}<\dot{F}_{f}^{c} & \dot{f}=0 \\
F_{f}=F_{f}^{c} & \text { and } \quad \dot{F}_{f}=\dot{F}_{f}^{c} & \dot{f}>0
\end{array}\right.
$$

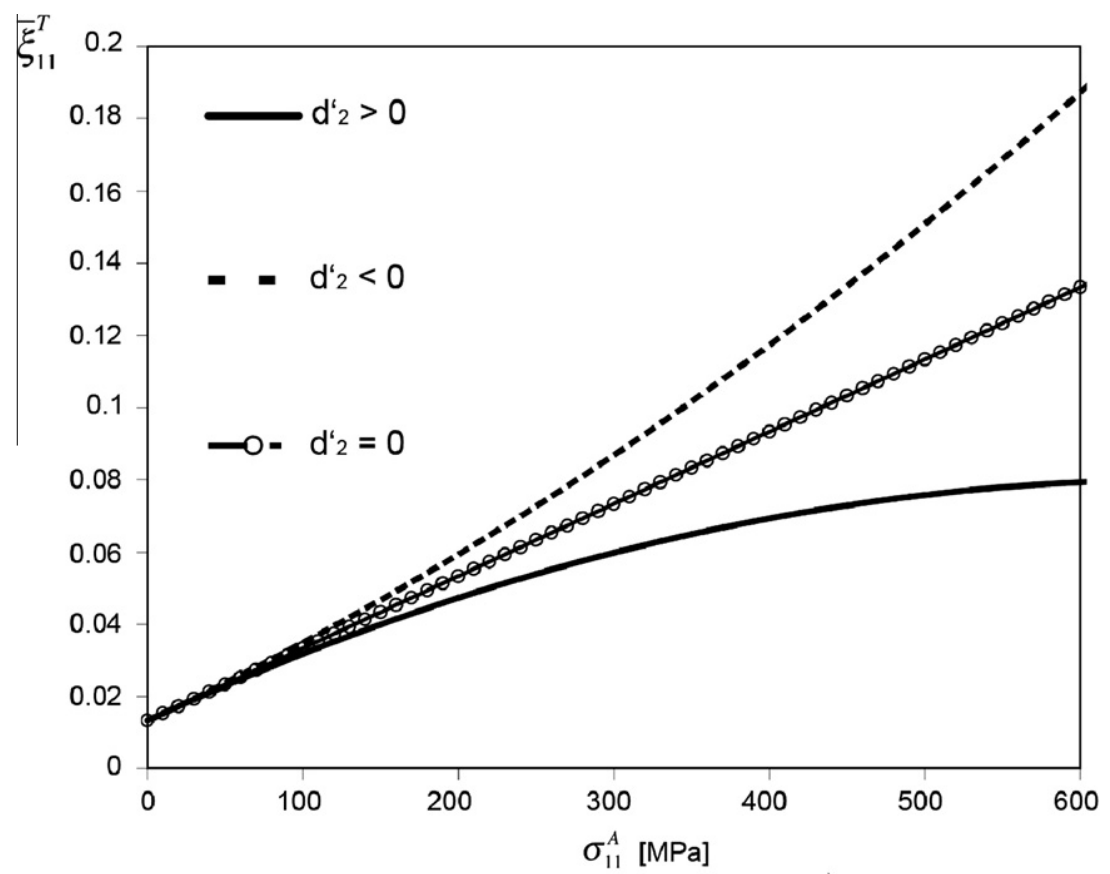

Fig. 5. Evolution of the Mean Instantaneous Transformation Strain (MITS) $\bar{\xi}_{11}^{T}$ component as a function of the stress component $\sigma_{11}^{A}$ during a tensile load in the austenitic phase. $\theta=4 \%, d_{1}^{\prime}=3 \cdot 10^{-4} \mathrm{MPa}^{-1}$. Effect of the value of $d_{2}^{\prime}, d_{2}^{\prime}= \pm 4 \cdot 10^{-7} \mathrm{MPa}^{-2}$. 

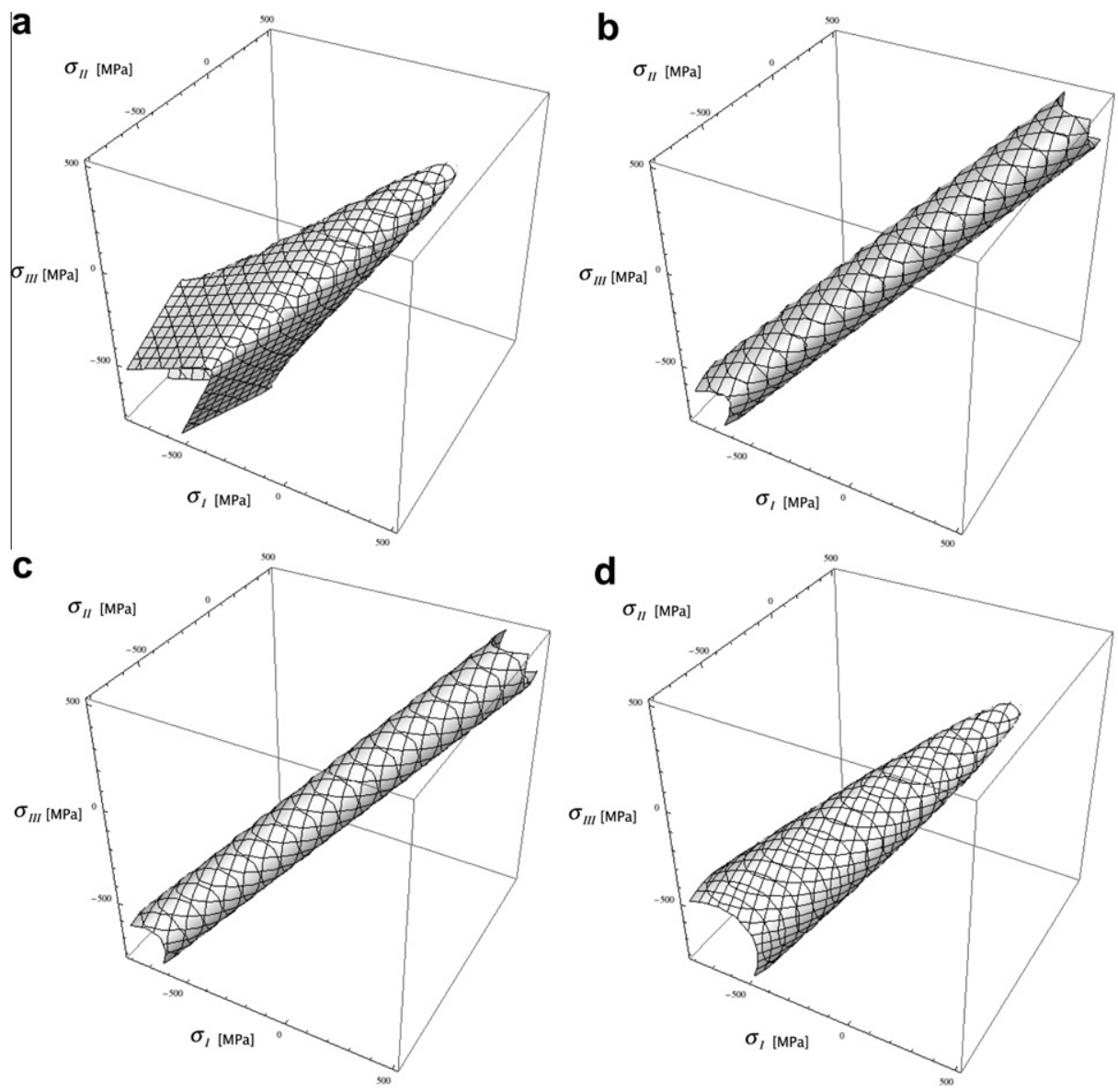

Fig. 6. Effect of the different parameters on the 3D transformation surface in the local principal stress reference system. (a) $\theta \neq 0, d_{2}^{\prime} \neq 0$, (b) $\theta=0, d_{2}^{\prime} \neq 0$, (c) $\theta=0, d_{2}^{\prime}=0$ and (d) $\theta \neq 0, d_{2}^{\prime}=0$.

A graphical representation of the transformation surface in the local principal stress reference system in austenite is presented in Fig. $6(3 \mathrm{D})$ and Fig. 7 (plane stress with $\sigma_{I I I}=0$ ). Inside the surface, there is no transformation evolution, $\dot{f}=0$. The surface is represented for the values, $\theta=4 \%, d_{1}^{\prime}=6 \cdot 10^{-4} \mathrm{MPa}^{-1}, d_{2}^{\prime}=-15 \cdot 10^{-7} \mathrm{MPa}^{-2}, F_{f}^{c}+K_{0}+B\left(T-T_{0}\right)=$ $10 \mathrm{MPa}$. The effect of the volume change $\theta$ via $I_{1}$ stress invariant is represented by the closing of the transformation surface along positive hydrostatic stress state (see Fig. $6 \mathrm{a}$ and d). For a pure negative hydrostatic stress state in austenite, no transformation is possible. In Fig. 7.a, the 2D representation of transformation surfaces is shown to exhibit a tension-compression asymmetry due partly to the volume change and to the non-linear expression of the MITS. When no volume change is assumed $(\theta=0)$, the asymmetric behavior between tension and compression is still predicted by the present model (Fig. 7b). The physical explanation is the selection of martensitic variants that are not the same in tension and in compression. In the mean-field model, the level of asymmetry is controlled by the value of parameter $d_{2}^{\prime}$.

\subsubsection{Critical forces and transformation kinetic}

The expression of the critical forces for irreversible martensitic transformation is based on physical concepts taking into account:

- the fact that the plastic flow of the austenitic phase assists the martensitic phase transformation (strain induced martensitic transformation),

- the martensitic topological hardening related with geometrical restrictions corresponding to the fact that the growth of martensitic domains is limited by already existing martensitic domains.

For the crystalline model, Cherkaoui et al. (1998) defined the critical resolved stress for the transformation of a martensitic variant $I$ as:

$$
\tau_{f_{l}}^{c}=\tau^{c_{o}}-k H^{h I} \gamma^{h A}+H_{f}^{I J} f^{J}
$$



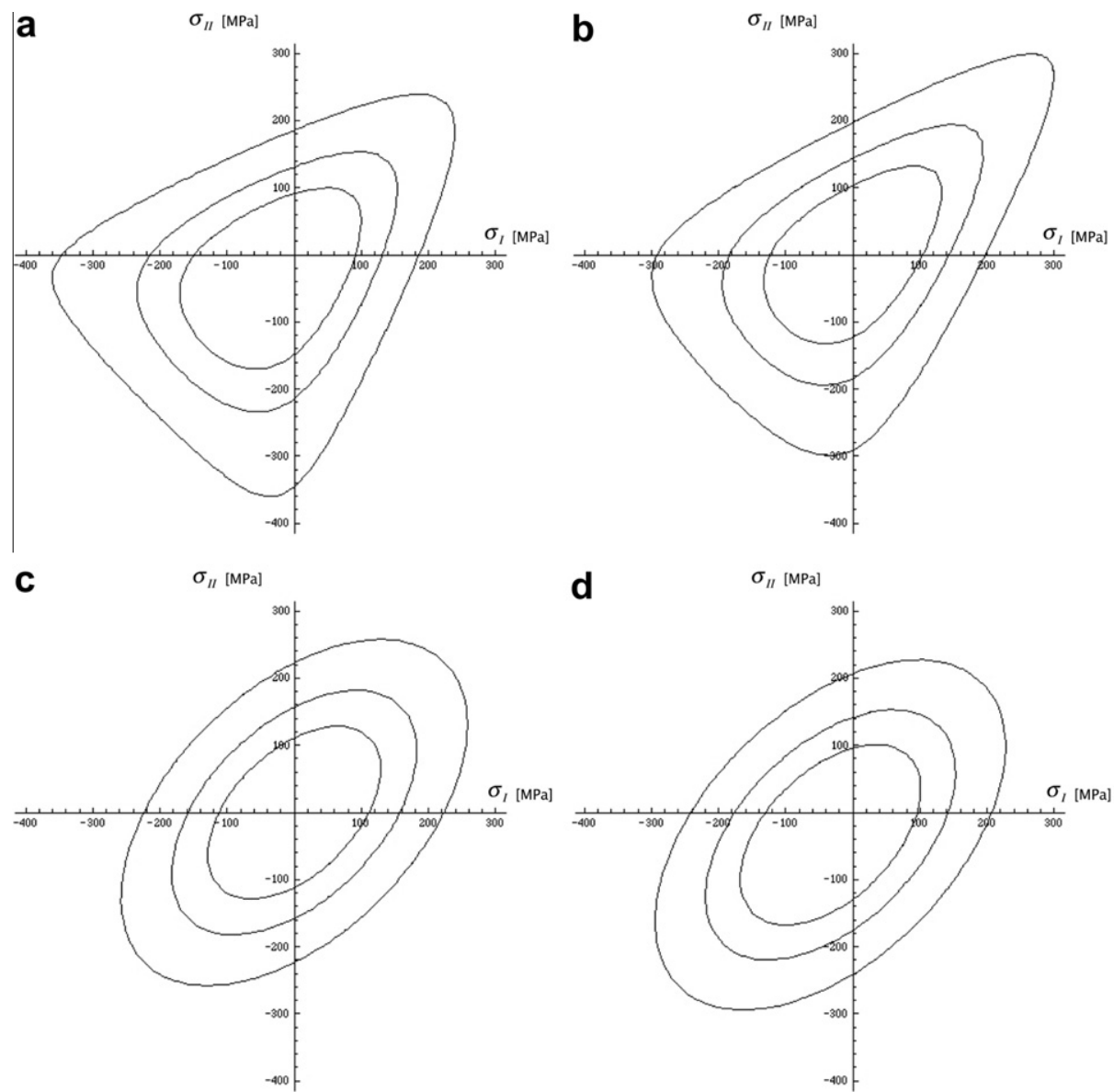

Fig. 7. Effect of the different parameters on the transformation surface for a $2 \mathrm{D}$ plane stress state in the local principal stress reference system. (a) $\theta \neq 0$, $d_{2}^{\prime} \neq 0$, (b) $\theta=0, d_{2}^{\prime} \neq 0$, (c) $\theta=0, d_{2}^{\prime}=0$ and (d) $\theta \neq 0, d_{2}^{\prime}=0$.

where $H^{h I}$ describes the strain assisted transformation and $H^{I I}$ corresponds to topological hardening due to the already formed martensite.

For the mean-field model, in order to model the transforming martensite that depends on already formed martensite of volume fraction $f$ and on the plastic strain in austenite $\varepsilon^{p_{A}}$, the critical force is defined as:

$$
F_{f}^{c}=F^{c_{0}}+K^{p}\left(\dot{\sim}^{p_{A}}\right)+K^{f}(f)
$$

where $K^{p}$ and $K^{f}$ are hardening functions with properties such as:

$$
\begin{aligned}
& K^{p}\left(\underset{\sim}{\varepsilon^{p_{A}}}=0\right)=0 \\
& K^{f}(f=0)=0
\end{aligned}
$$

For the hardening due to plasticity, it is assumed that local plastic strain state promote martensitic transformation (i.e. lowers the critical force for transformation, with $k>0$ ):

$$
K^{p}=-k\left(\varepsilon_{e q}^{p_{A}}\right)^{n}
$$

where $k$ and $n$ are two parameters and $\varepsilon_{e q}^{p_{A}}$ the equivalent plastic strain in austenite. The $K^{p}$ function takes into account the strain induced transformation domain $\left(T>M_{S}^{\sigma}\right)$, where a plastic pre-strain helps the onset of martensitic transformation. The physical origin is the creation of martensite at the intersection of slip bands or due to stress fluctuations at the level of dislocations. The $K^{f}$ function represents the effect of the already formed martensite on the currently forming one. Similar to a Johnson-Mehl-Avrami equation, the following expression is proposed:

$$
K^{f}=-\kappa \cdot \ln (1-f)
$$


where $\kappa$ is a hardening parameter controlling the effect of the amount of martensite already formed.

$F^{C_{0}}$ is the initial critical force to be reached for martensitic transformation for a cooling at no stress. Without any local stress (i.e. $\sigma^{A}=0$ ), martensitic transformation starts at $T=M_{S}$ so that $F_{f}=F_{f}^{c}$. Thus using the expression of the driving force (79), the initial critical force is determined:

$$
F^{C_{0}}=-B\left(M_{S}-T_{0}\right)-K_{0}
$$

When the driving force reaches the critical force (i.e. $F_{f}=F_{f}^{c}$ ), the consistency rule (i.e. $\dot{F}_{f}=\dot{F}_{f}^{c}$ ) of the transformation criterion (80) leads to the determination of the martensitic kinetic with:

$$
\left\{\begin{array}{l}
\dot{F}_{f}=\dot{\sim}^{A}:{\underset{\sim}{\xi}}^{\bar{\xi}^{T}}+\underset{\sim}{\sigma^{A}}: \underset{\sim}{\dot{\xi}^{T}}-B \cdot \dot{T} \\
\dot{F}_{f}^{c}=\frac{\kappa}{1-f} \cdot \dot{f}+\dot{K}^{p}\left({\underset{\sim}{\varepsilon^{p}}}^{p_{A}}\right)
\end{array}\right.
$$

Assuming that the MITS is constant during the transformation of an infinitesimal volume fraction $\dot{f}$ of martensite (i.e. $\dot{\vec{\xi}}^{T}=0$ ), the transformation kinetic is derived from Eq. (87) as:

$$
\dot{f}=\frac{1-f}{\kappa}\left(\dot{\sigma}_{\sim}^{A}: \underset{\sim}{\dot{\xi}^{T}}-B \cdot \dot{T}-\dot{K}^{p}\left(\underset{\sim}{\varepsilon^{p_{A}}}\right)\right)
$$

The evolution of the martensitic volume fraction is controlled by the stress, thermal and plastic strain increments in austenite. The relation (88) captures both the stress assisted and the strain induced martensitic nucleation mechanisms. If only the thermal part is taken into account, Eq. (88) renders the classical Koistinen-Marburger equation.

\section{Multiscale modelling of the behavior of TRIP steels}

In heterogeneous materials, linking the overall strain rate $\dot{E}$ to the control variables $(\dot{\Sigma}, \dot{T})$ requires a multiscale model. A two-level self-consistent scheme is developed for the thermomechanical modelling of a multiphased TRIP aided steel. A first level of the self-consistent scheme allows to concentrate the strain in each phase (ferrite, bainite and unstable austenite with the transforming martensite). The second level of transition is the concentration from the strain rate in unstable austenite $\gamma$ with the transforming martensite to the residual austenitic phase and the transformed martensitic domains. In this section, we focus on the description of the second level of the self-consistent scheme from the $\gamma$ phase to austenite $(A)$ and martensite $(M)$. This transition is the only one in case of an entirely austenitic steel $\left(F^{\gamma}=1\right)$. The local interactions between the thermomechanical behaviors of phases (thermoelastoplasticity with MITS) are described. Through strain rate concentration and homogenisation steps, an expression of the global transformation strain rate $\dot{E}^{T}$ is derived.

\subsection{Strain rate concentration}

In order to link the local strain rate in phase $A$ and $M$ to the global one in phase $\gamma$ when submitted to the control variables $(\dot{E}, \dot{f}, \dot{T})$, strain rate concentration tensors are derived as presented in detail in Appendix C. The local strain rate is expressed as follows:

$$
\underset{\sim}{\dot{\varepsilon}}=\underset{\approx}{A}: \underset{\sim}{\dot{E}}+\underset{\sim}{a} \dot{f}+\underset{\sim}{\alpha} \cdot \dot{T}
$$

where $\underset{\sim}{A} \underset{\sim}{a}$ and $\underset{\sim}{\alpha}$ are respectively the concentration tensors for the macroscopic strain, transformation and temperature rates. The classical self-consistent scheme (Berveiller, 1981) is adapted to the determination of the effective macroscopic properties $\underset{\sim}{\text { eff }}, M_{\sim}^{\text {eff }}, N_{\sim}^{\text {eff }}$ of an heterogeneous elastoplastic material exhibiting martensitic transformation. Those quantities are used in the expression of the macroscopic homogenized behavior law such as:

$$
\underset{\sim}{\dot{\Sigma}}=\underset{\approx}{\text { eff }^{e f}}: \underset{\sim}{\dot{E}}-\underset{\sim}{N^{e f f}} \dot{f}-M_{\sim}^{\text {eff }} \cdot \dot{T}
$$

In Appendix C, the concentration tensors are derived:

$$
\begin{aligned}
& \underset{\approx}{A}=\left[\underset{\approx}{I}-\underset{\approx}{\Gamma^{l}}:\left(\underset{\approx}{e p p}-\underset{\approx}{L^{e f f}}\right)\right]^{-1} \\
& \underset{\sim}{a}=-\underset{\approx}{A}: \Gamma_{\approx}^{l}:\left(\underset{\sim}{n}-\underset{\sim}{N^{e f f}}\right) \\
& \underset{\sim}{\alpha}=-\underset{\approx}{A}: \Gamma_{\approx}^{l}:\left(\underset{\sim}{m}-M_{\sim}^{\text {eff }}\right)
\end{aligned}
$$

where $\Gamma_{\approx}^{l}$ is the local part of the modified Green tensor.

\subsection{Homogenisation of the behavior of the $\gamma$ phase}

Eq. (64) expresses local behavior laws in $A$ and $M$ as: 


$$
\underset{\sim}{\dot{\sigma}}=\underset{\approx}{l^{e p}}: \underset{\sim}{\dot{\varepsilon}}-\underset{\sim}{n} \cdot \dot{f}-\underset{\sim}{m} \cdot \dot{T}
$$

By using the local representation of the behavior (Eq. (92)) and the strain rate concentration relation (89), the global behavior law of the $\gamma$ phase is written as:

$$
\underset{\sim}{\dot{\Sigma}}=\langle\underset{\sim}{\dot{\sigma}}\rangle=\left\langle\underset{\approx}{l^{e p}}: \underset{\approx}{A}\right\rangle: \underset{\sim}{\dot{E}}+\left\langle\underset{\approx}{l^{e p}}: \underset{\sim}{a}-\underset{\sim}{n}\right\rangle \dot{f}+\left\langle\underset{\approx}{l^{e p}}: \underset{\sim}{\alpha}-\underset{\sim}{m}\right\rangle \dot{T}
$$

The effective macroscopic moduli are identified by comparing Eq. (93) to Eq. (90):

$$
\begin{aligned}
& \underset{\approx}{L^{e f f}}=\left\langle\underset{\approx}{l^{e p}: A}\right\rangle \\
& N_{\sim}^{e f f}=\left\langle\underset{\sim}{\left.n-l_{\approx}^{e p}: \underset{\sim}{a}\right\rangle}\right. \\
& {\underset{\sim}{\sim}}^{e f f}=\left\langle\underset{\sim}{\operatorname{m}}-\underset{\approx}{l^{e p}}: \underset{\sim}{\alpha}\right\rangle
\end{aligned}
$$

where \langle\rangle is the averaging operator over the RVE.

The macroscopic behavior is also given as a function of the macroscopic transformation strain rate $\dot{\sim}_{\sim}^{T}$ :

$$
\underset{\sim}{\dot{\Sigma}}=\underset{\approx}{L^{e f f}}:\left(\underset{\sim}{\dot{E}}-\dot{\sim}^{T}\right)-{\underset{\sim}{\text { Meff }}}^{\text {e }} \dot{T}
$$

By comparing Eqs. (90)-(95), the transformation strain rate is identified as:

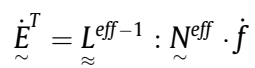

$N_{\sim}^{e f f}$ is explicitly derived by inserting Eq. (66) in Eq. (94) such as:

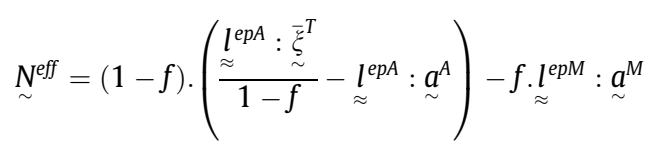

Since

$$
\langle\underset{\sim}{a}\rangle=0 \quad \text { i.e. } f \cdot a_{\sim}^{M}=-(1-f) \cdot{\underset{\sim}{a}}^{A}
$$

the macroscopic transformation strain rate (Eq. (96)) is finally derived such as:

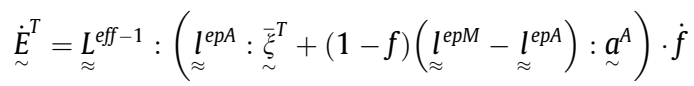

It can be noticed that, at the beginning of the transformation, where $f=0, l^{\text {epA }}=L^{\text {eff }}$ and $a^{A}=0$, or if behaviors of austenite and martensite are identical (i.e. $\underset{\approx}{l e p A}=\underset{\approx}{l e p M}=\underset{\approx}{L^{e f f}}$ ), the transformãtion $\tilde{\widetilde{s}}$ train rate (99) is reduced to the expression:

$$
\dot{\sim}^{T}={\underset{\sim}{\xi}}^{T} \dot{f}
$$

The latter condition is the case of shape memory alloys where behaviors of austenite and martensite are only elastic and identical $\left(C^{A}=C^{M}\right)$. Hence, only the Magee effect is rendered.

For the $\widetilde{\approx}$ description of the TRIP effect, there is additional plastic flow in austenite induced by transformation. As underlined by Diani et al. (1995), the macroscopic transformation strain characteristic of a TRIP effect is such as:

$$
\dot{\sim}^{T} \neq{\underset{\sim}{\xi}}^{T} \dot{f}
$$

\section{Application to multiaxial thermomechanical behaviors of a RVE with TRIP effect}

The constitutive equations of the model presented in Section 4 for the description of the elementary processes and in Section 5 for the derivation of the overall behavior (Eq. (90)) are implemented in a Fortran 77 program. A Newton-Raphson correction procedure is used to control the convergence of the simulation. The response of the model is tested for entirely austenitic steel grade and a multiphased TRIP steel. Cooling simulations at a constant stress and monotonic radial loading paths at a constant temperature are tested. For monotonic tests, no kinematical hardening is taken into account in this section (i.e. $X=0$ ). The model is also used for the simulation of different monotonic loading paths of a multiphase TRIP aided steel compared to experiments performed by Furnemont (2003). 


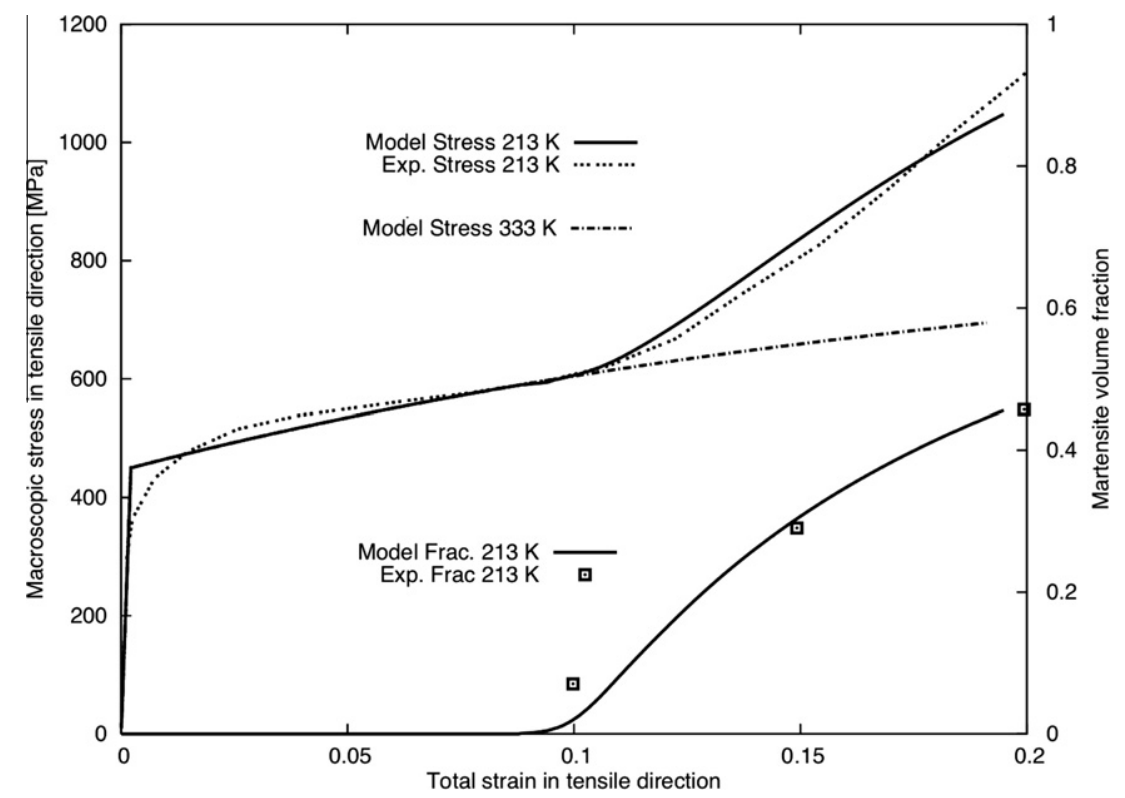

Fig. 8. Stress-strain behavior and martensite volume fraction of an entire metastable austenitic steel under uniaxial tension at $213 \mathrm{~K}$ and at $333 \mathrm{~K}$. Experiment vs model.

Table 1

Hardening parameters for austenite $\gamma$ and martensite $\alpha^{\prime}$ for an austenitic steel (AISI304).

\begin{tabular}{|c|c|c|c|}
\hline & $\sigma_{y}(\mathrm{MPa})$ & $Q_{0}(\mathrm{MPa})$ & $b$ \\
\hline$\gamma$ & 450 & 400 & 5 \\
\hline$\alpha^{\prime}$ & 1000 & 1000 & 20 \\
\hline
\end{tabular}

\subsection{Austenitic steel grade}

The case of an entire austenitic steel $\left(F^{\gamma}=1\right.$ and $\left.f=0\right)$ is analysed. The model parameters are calibrated with experimental tensile data (stress vs strain curve and martensitic volume fraction) available on AISI304 steel grade at $213 \mathrm{~K}$ (Kubler et al., 2003).

\subsubsection{Tensile test on a metastable austenitic steel}

The modelled stress vs strain behavior is presented on Fig. 8 with the corresponding evolution of martensitic volume fraction. The hardening parameters of austenite and martensite are presented in Table 1. They are identified with the experimental stress-strain curve previous to transformation for austenite and at saturation for martensite. The parameters describing transformation (Table 2) are identified according to the experimental evolution of martensitic volume fraction. $M_{S}$ temperature of AISI304 is measured at $70 \mathrm{~K}$ and the volume change is $4 \% . B$ is set to $2 \mathrm{MPa} / \mathrm{K}$ as seen in Bumbieler (1999). $K_{0}, d_{1}^{\prime}$, $d_{2}^{\prime}$, $\kappa, k$ and $n$ are identified to calibrate the start and the evolution of martensitic volume fraction.

On the stress vs strain curve of Fig. 8, we can observe that the model predicts the increase of the hardening coefficient with the evolution of the martensitic volume fraction. In Figs. 8 and 9, the behavior with transformation is compared to the behavior without transformation. In Fig. 9, the focus is made on the dynamic softening effect at the onset of martensitic transformation which is reproduced by the model. The stress-strain curve with transformation passes below the curve without transformation exhibiting the sudden increase of transformation strain as described by Olson and Cohen (1982).

\subsubsection{Cooling at constant stress level of metastable austenite}

At different tensile stresses, the material is cooled down from $493 \mathrm{~K}$. The modelling parameters are identical to the one presented in Tables 1 and 2. The isotropic dilatation coefficients for austenite $\gamma$ and martensite $\alpha^{\prime}$ are respectively $24.5 \cdot 10^{-6} \mathrm{~K}^{-1}$ and $11.5 \cdot 10^{-6} \mathrm{~K}^{-1}$ (Jaramillo and Lusk, 2004).

\section{Table 2}

Parameters describing the transformation for an austenitic steel (AISI304).

\begin{tabular}{lllllllll}
\hline$M_{s}(\mathrm{~K})$ & $B(\mathrm{MPa} / \mathrm{K})$ & $K_{0}(\mathrm{MPa})$ & $\kappa$ & $\Delta V / V$ & $d_{1}^{\prime}\left(\mathrm{MPa}^{-1}\right)$ & $d_{2}^{\prime}\left(\mathrm{MPa}^{-2}\right)$ & $k$ & $n$ \\
\hline 70 & 2 & 20 & 1 & 0.04 & $2 \cdot 10^{-5}$ & $-2 \cdot 10^{-7}$ & 400 & $1 / 3$ \\
\hline
\end{tabular}




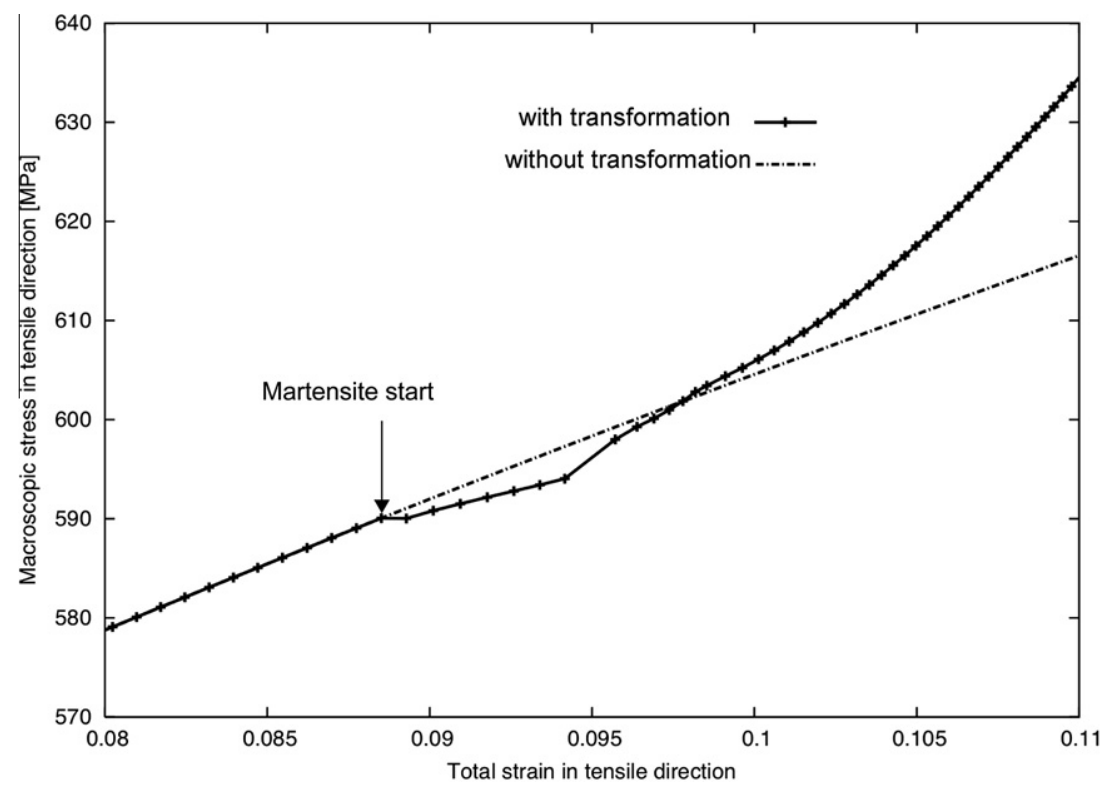

Fig. 9. Comparison between the stress-strain behavior with and without martensitic transformation under uniaxial tension at $213 \mathrm{~K}$. Dynamic softening appears at the beginning of the transformation.

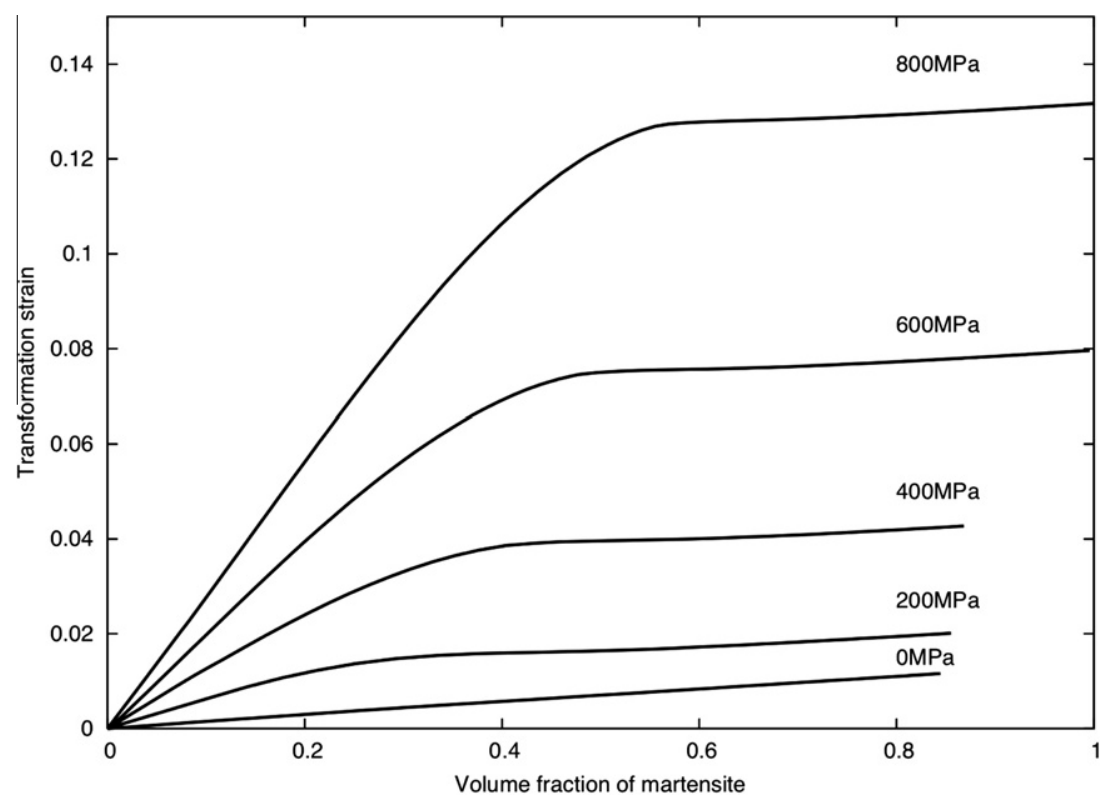

Fig. 10. Transformation strain in the tensile direction vs. volume fraction of martensite for cooling at different stress levels.

Fig. 10 represents the transformation strain in the tensile direction $\left(E_{11}^{T}\right)$ vs. volume fraction of martensite. When martensitic transformation occurs, the transformation strain increases until the saturation of martensitic volume fraction. Under no macroscopic stress, transformation starts at temperature $M_{s}$. It can be observed that the initial slope at $f=0$ increases with the applied stress level. This initial slope defined as $\dot{E}_{11}^{T} / \dot{f}$ is the MITS as expressed in Eq. (100). It is the signature of the variant selection by their orientation with respect to the stress (i.e. Magee effect). The transformation strain at saturation increases with the applied stress agreeing qualitatively with experimental results in the literature (Bumbieler, 1999; Gautier, 1985; Petit-Grostabussiat et al., 2004).

The evolution of the mean instantaneous transformation strain (MITS) along the tensile direction versus the martensitic volume fraction is shown in Fig. 11. As seen in the MITS formulation (78), the initial value of the MITS increases with the local stress in austenite, which is the applied stress at the start of the transformation. At a constant applied stress, when martens- 


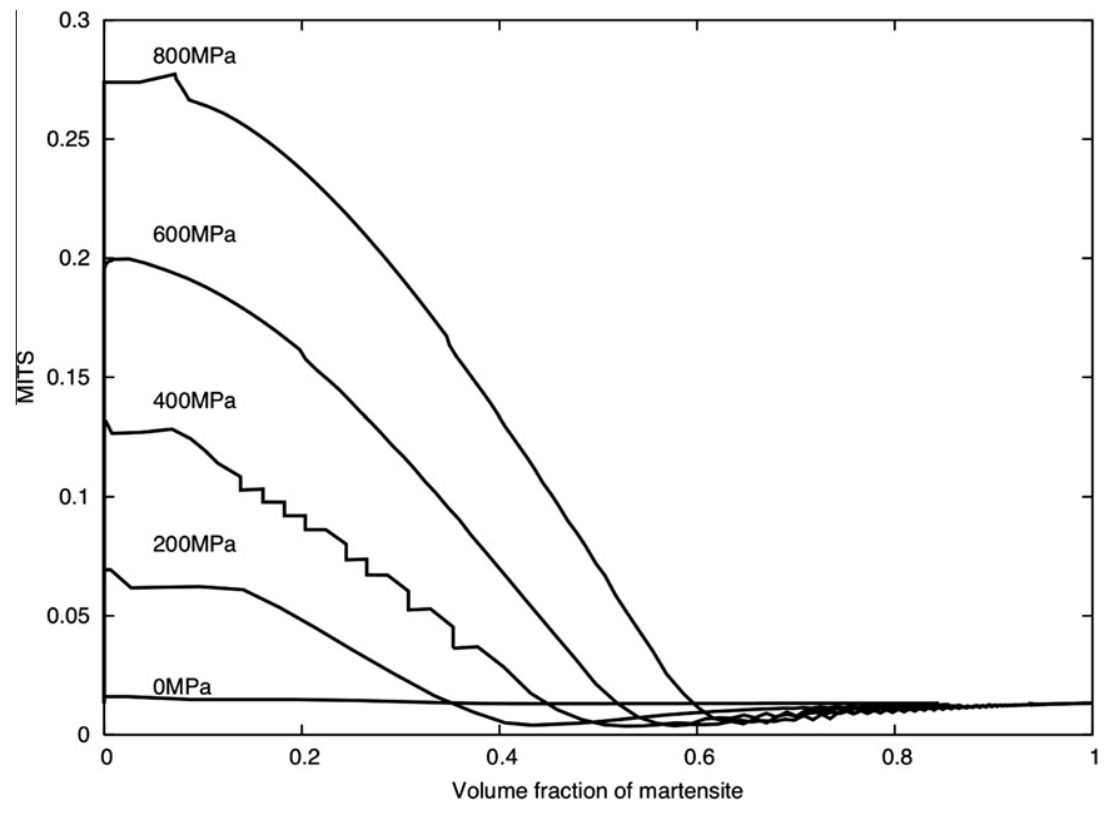

Fig. 11. MITS in the tensile direction vs. volume fraction of martensite for cooling at different stress levels.

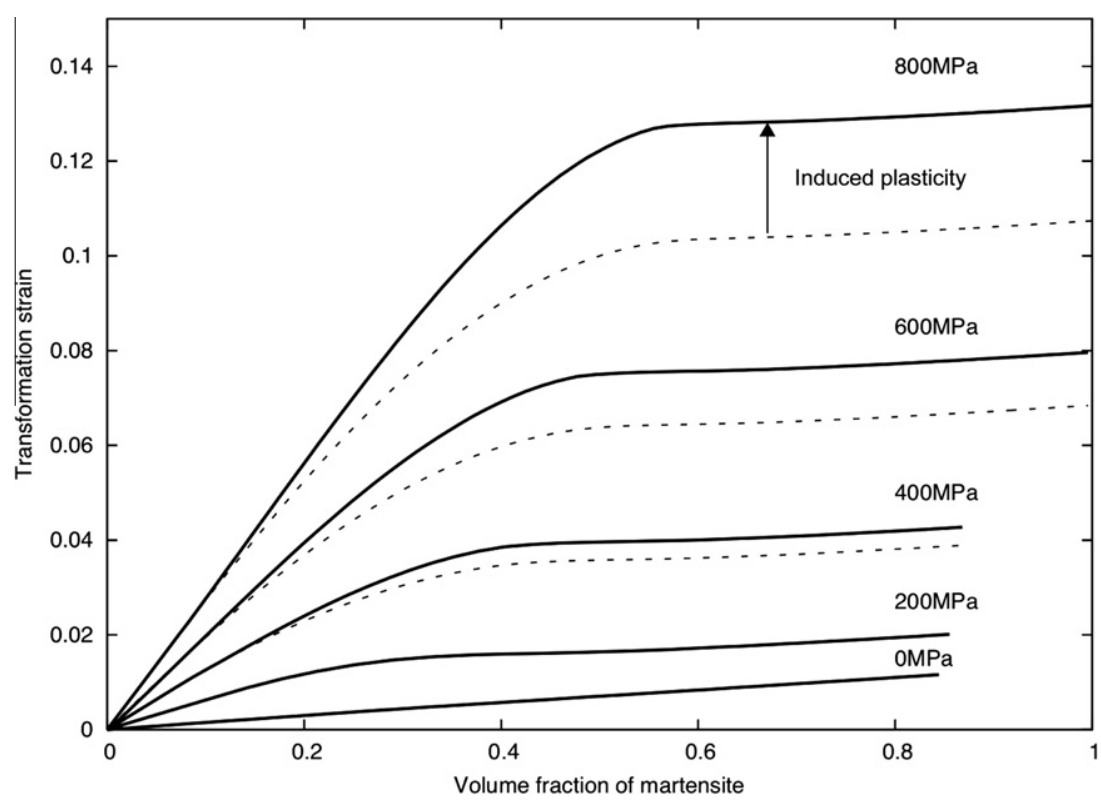

Fig. 12. Transformation strain in the tensile direction vs. volume fraction of martensite for cooling at different stress levels. Transformation induced plasticity (solid line) compared to transformation without induced plasticity (dashed line).

ite is created, the stress distribution between austenite and martensite evolves (Kubler et al., 2002). The average stress in austenite decreases balanced by the stress in the created martensite. The consequence is that the MITS is also decreasing and the transformation strain is less oriented when martensitic transformation progresses.

When the transformation progresses, plastic yielding occurs in austenite if the yield stress is reached, allowing transformation induced plasticity. The transformation strain includes the part of the Greenwood Johnson effect describing the plastic accommodation in the austenitic phase. Fig. 12 compares the total transformation strain $E_{11}^{T}$ with the accumulated MITS defined as: 


$$
\int_{0}^{t} \bar{\xi}_{11}^{T} \dot{f} d t
$$

At the beginning of the transformation both quantities are the same and an additional accommodating strain appears and increases with the applied load if the yield stress of austenite is reached. As a consequence, for cooling at an applied stress of $200 \mathrm{MPa}$, no transformation induced plasticity is predicted. However, at an applied stress of $400 \mathrm{MPa}$, some induced plasticity is added to the total strain.

\subsection{Multiphase TRIP 800 steel}

\subsubsection{Tensile test on a multiphase TRIP 800 steel at room temperature}

The simulation of a tensile test of a TRIP 800 steel grade $(0.2 \% \mathrm{C}, 1.65 \% \mathrm{Mn}, 1.65 \% \mathrm{Si})$ at $300 \mathrm{~K}$ is presented in Fig. 13 and is compared to the experimental behavior (Hourman et al., 2000). The proportions of different phases are $F^{\gamma}=16.5 \%$ of metastable austenite, $F^{\alpha}=70 \%$ of ferrite and $F^{b}=13.5 \%$ of bainite. The hardening parameters of the different phases are identified from the only knowledge of the macroscopic response (Table 3). The average behavior of the ferrite-bainite mixture is in good agreement with experimental data from the literature (Furnemont, 2003). In this multiphase material, the behavior of ferrite and bainite cannot be differentiated by diffraction methods (Delannay et al., 2008). The yield strength of martensite is set to $2 \mathrm{GPa}$ (Jacques et al., 2007). The $M_{S}$ temperature is measured by differential scanning calorimetry and set to $190 \mathrm{~K}$. In Fig. 13, the evolution of the volume fraction of residual austenite is plot as a function of the total tensile strain during the tensile test. In comparison with entirely austenitic steels, the TRIP signature (i.e. increase of stress level) is less obvious with the transformation evolution. Martensitic transformation occurs at the first stage of plastic strain. The martensitic volume fraction reaches $75 \%$ of the initial austenitic phase at a total strain of $22 \%$.

In Fig. 14, the instantaneous hardening coefficient $n$ is plot as a function of the total strain. The instantaneous hardening coefficient $n$ is defined as:

$$
n=\left(d \Sigma_{11} / d E_{11}\right) \cdot\left(E_{11} / \Sigma_{11}\right)
$$

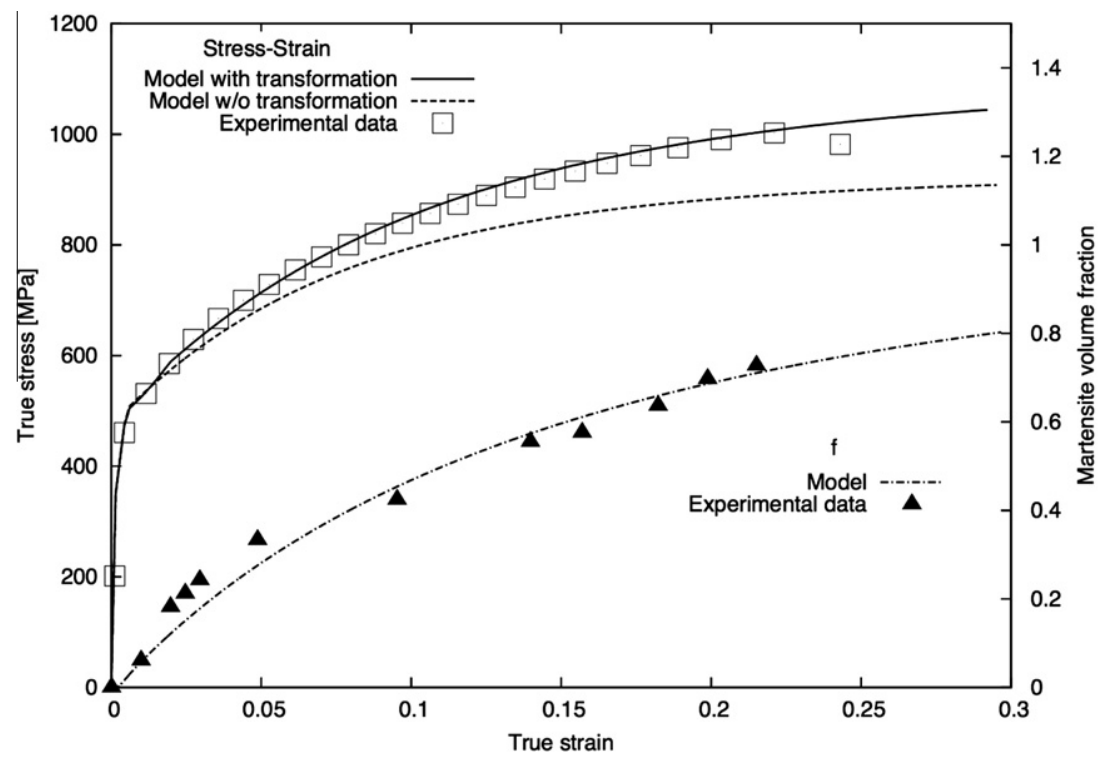

Fig. 13. Stress strain behavior (with and without transformation) and martensite volume fraction in uniaxial tension at $T=300 \mathrm{~K}$. Model vs. experimental data (Hourman et al., 2000).

Table 3

Hardening parameters for TRIP 800.

\begin{tabular}{lcrr}
\hline & $\sigma_{y}(\mathrm{MPa})$ & $Q_{0}(\mathrm{MPa})$ & $b$ \\
\hline$\gamma$ & 300 & 400 & 5 \\
$\alpha^{\prime}$ & 1000 & 1000 & 20 \\
Ferrite & 350 & 280 & 10 \\
Bainite & 950 & 1200 & 20 \\
\hline
\end{tabular}




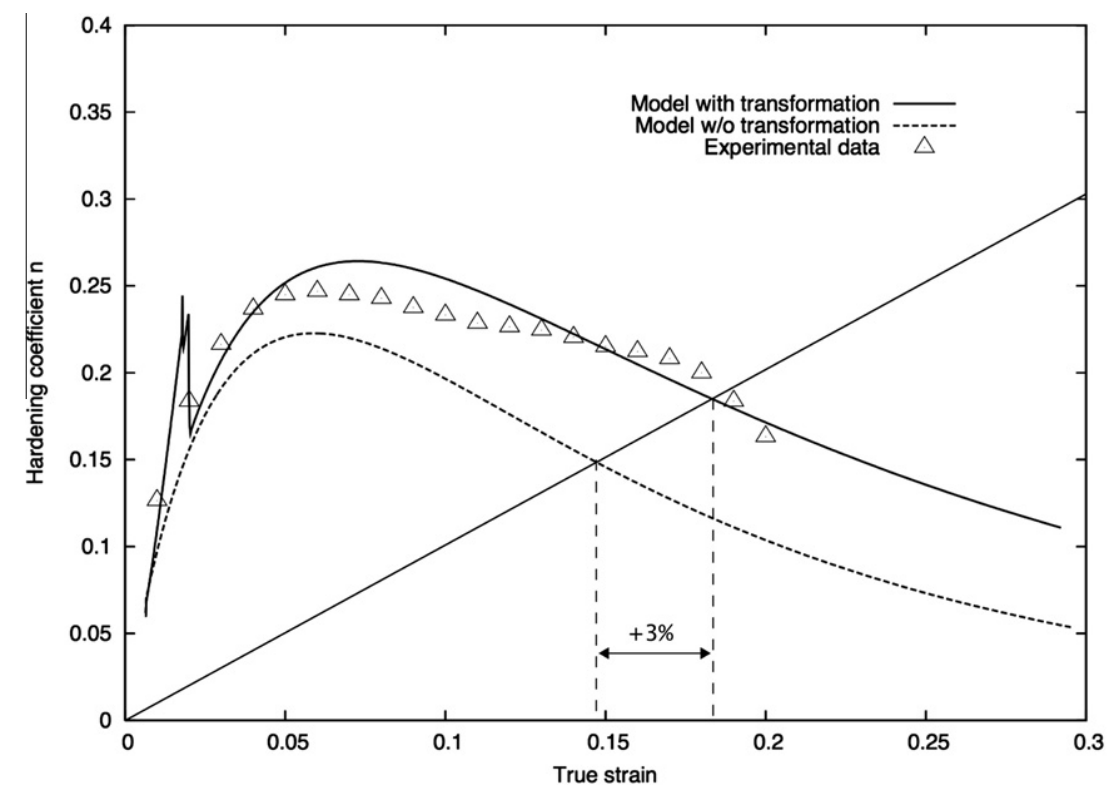

Fig. 14. Evolution of the hardening coefficient $n=(d \Sigma / d E) .(E / \Sigma)$ during the tensile test (with and without transformation). Increase of $3 \%$ of the ductility. Model vs. experimental data.

To underline the effect of martensitic transformation on the ductility property, the simulation is run without martensitic transformation and compared on Figs. 13 and 14 to the one with martensitic transformation. On Fig. 13, it is observed that the model predicts a weaker stress when martensitic transformation is not taken into account. Moreover, Considere's necking criterion predicts necking (i.e. loss of ductility), if $n=\varepsilon$. Applying this criterion to TRIP 800 exhibiting martensitic transformation, the model predicts that the transformation induced plasticity effect delays the necking by $3 \%$ compared to a multiphased material without TRIP effect (Fig. 14). This increase of ductility of $3 \%$ corresponds to a volume fraction of formed martensite of $65 \%$ in the austenitic phase representing only $16.5 \%$ of the total volume. Hence, the new model predicts the increase in strength and ductility when martensitic transformation and the resulting TRIP effect are taken into account.

\subsection{Multiaxial loadings on a multiphase TRIP steel}

The mean-field model is applied to predict the behavior of a multiphase TRIP steel submitted to multiaxial loading paths and compared to the literature experimental results obtained by Furnemont (2003). The chemical composition is $0.29 \%$, $1.42 \% \mathrm{Mn}, 1.41 \% \mathrm{Si}$ with phase proportions such as $F^{\gamma}=17.5 \%$ of metastable austenite, $F^{\alpha}=55 \%$ of ferrite and $F^{b}=27.5 \%$ of bainite. Tensile, shear and biaxial tests as well as volume fraction determination at room temperature are performed. Moreover, the local stress-strain behavior of austenite and ferrite and bainite was measured during a tensile test with neutron diffraction. The hardening parameters (Table 4) are identified from the local tensile behaviors. Transformation parameters are identified from the global behavior laws and from the volume fraction of residual austenite for the tensile and shear tests in order to fit the experimental volume fraction of austenite. The experimental (Furnemont, 2003) and modelling results are presented in Fig. 15. A biaxial tension is simulated and the evolution of volume fraction of residual austenite is compared to experimental data. Good agreements are obtained according to the volume fraction of residual austenite. Above a total strain of $15 \%$, the predicted volume fraction in shear is underestimated. For the tensile stress-strain curve, the light difference between experimental results and simulation is due to martensite transforming before the austenite yield stress is reached, which is not the case with the calibrated parameters. From these comparisons between different loading paths, it is observed that at room temperature biaxial tension favors martensitic transformation before plastic yielding in austenite. The multiaxial characteristic of this new model is explicitly shown with the 2D transformation surface in Fig. 16 for the identified

Table 4

Hardening parameters for $0.29 \% \mathrm{C}, 1.42 \% \mathrm{Mn}, 1.41 \% \mathrm{Si}$ TRIP steel.

\begin{tabular}{lcrr}
\hline & $\sigma_{y}(\mathrm{MPa})$ & $Q_{0}(\mathrm{MPa})$ & \multicolumn{1}{c}{} \\
\hline$\gamma$ & 720 & 800 & 5 \\
$\alpha^{\prime}$ & 2000 & 3000 & 10 \\
Ferrite & 300 & 400 & 5 \\
Bainite & 950 & 500 & 15 \\
\hline
\end{tabular}



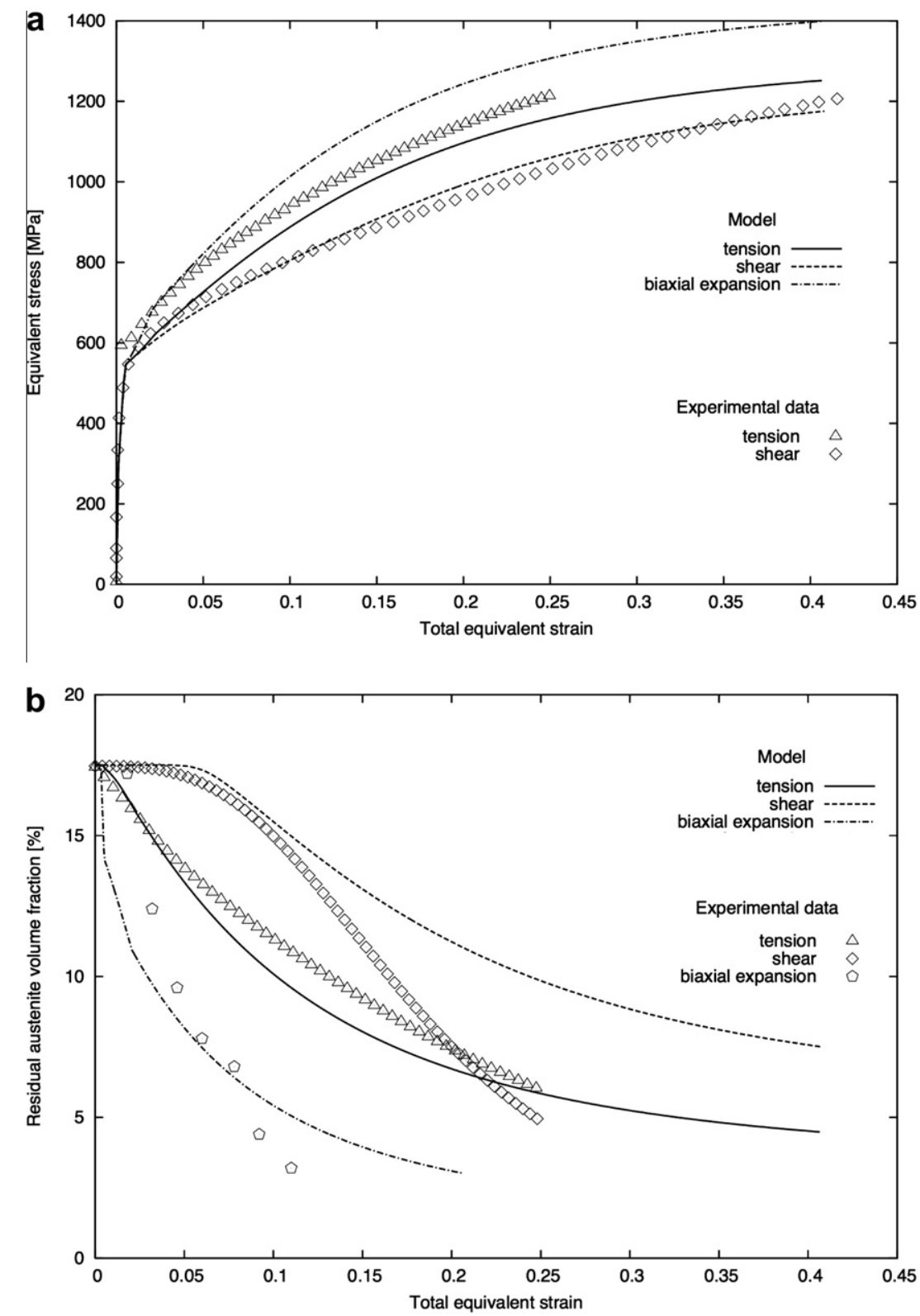

Fig. 15. Simulation vs experimental results (Furnemont, 2003) for multiaxial loadings (tension, shear, biaxial tension). (a) Equivalent stress vs equivalent strain. (b) Residual austenite volume fraction vs equivalent strain.

parameters. The transformation surface is compared to the yield surface of austenite in the macroscopic $\Sigma_{11}-\Sigma_{22}$ reference system. It is seen that for uniaxial tension, the yield stress in austenite is reached at the same time as martensite transforms. For loading paths between uniaxial tension and biaxial tension, martensitic transformation precedes plastic flow in austenite, whereas for other loading paths, plastic flow occurs first. A finer optimisation of the parameters of the model has still to be carried out.

\section{Conclusions}

The development of a new semi-phenomenological model of the thermomechanical behavior of TRIP aided steels has been presented in this work. It is based on a mean-field description of the plastic and transformation strains in the different phases. Deriving constitutive equations at the phase level in residual austenite transforming into martensitic domains, the concept of Mean Instantaneous Transformation Strain $\bar{\xi}^{T}$ (MITS) is introduced. The MITS averages the contribution of the 


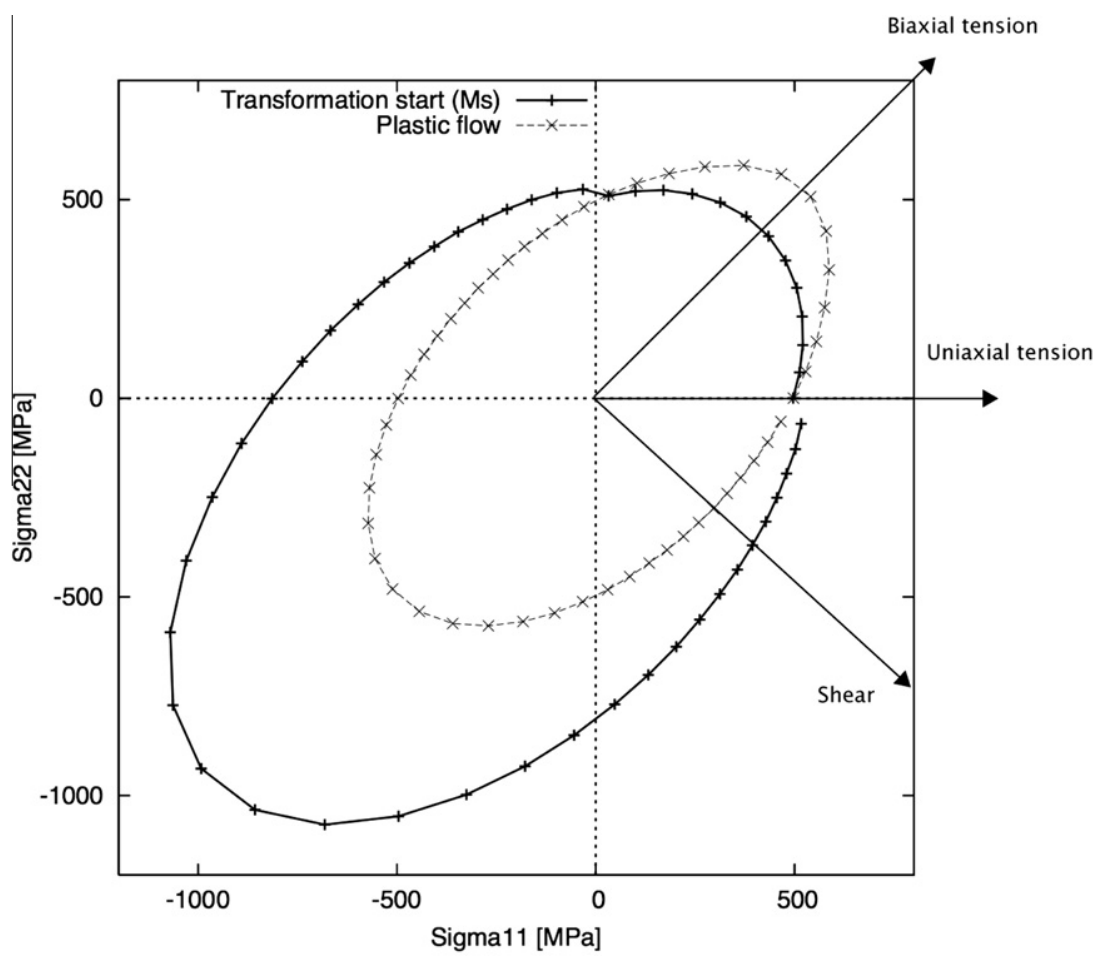

Fig. 16. Transformation and yield surfaces of austenite in the macroscopic coordinate system $\Sigma_{11}-\Sigma_{22}$ for the identified parameters.

transforming domains in the RVE. To capture the saturation of the Magee effect with the local stress state, a non-linear dependance of the MITS with the local stress in austenite is adopted. A transformation criterion based on the stress invariants in austenite $I_{1}-J_{2}-J_{3}$ is derived resulting in an induced anisotropy of martensitic transformation, as observed experimentally. This new criterion underlines that the tension-compression asymmetry usually observed in martensitic transformation is not only due to the volume variation from austenite to martensite. The non-linear dependence of the MITS (i.e. the saturation of the transformation strain with the local stress) plays an important role in the asymmetric response.

Discussions according to the multiaxial transformation criterion and its representation (2D and 3D) give strong insights about the number of parameters needed to capture the effects of martensitic transformation and their influences on the global response for a non-reductive modelling of the thermomechanical behavior of TRIP steels. The Greenwood Johnson effect is captured via the classical self-consistent scheme (i.e. $\dot{E}^{T} \neq \dot{f}^{T}$ ). The proposed model is suited for cooling tests and multiaxial loadings. It is tested for cooling at constant stress and uniaxial loading at different temperatures for entirely austenitic steels. Through scale transition equations, the ability to capture the dynamic softening effect at the onset of martensitic transformation is shown. For industrial multiphase TRIP steels, the model gives valid estimates of the macroscopic stress-strain behavior as well as the evolution of martensitic transformation under different loading conditions. The model showed an increase of $3 \%$ in ductility when martensitic transformation is considered within a multiphase TRIP steel with $16.5 \%$ of metastable austenite.

The advantage of this semi-phenomenological model compared to a crystallographic model as presented in this work is that the number of internal variables are reduced to the global volume fraction, the elastoplastic strain in each phase and the MITS. Thus, the reduced cost of this type of model, capturing the effects of transformation on the global behavior, should permit its use in simulations of metal forming processes. Due to the anisotropy of the martensitic transformation, an accurate calibration of the present model at a given temperature requires three distinct loading paths (tension, biaxial expansion, shear) with martensitic volume fraction determination.

The model has been fully detailed in order to be readily implemented in an user subroutine of a finite element code for on-going work on metal forming simulations (Kubler et al., 2010) of TRIP steels.

\section{Acknowledgment}

The authors are grateful to ArcelorMittal R\&D for supporting this research. 


\begin{tabular}{|c|c|}
\hline Symbols & Definition \\
\hline$\underline{u}$ & Displacement vector \\
\hline$\underset{\sim}{E}$ & Total macroscopic strain tensor \\
\hline$E_{\sim}^{T p}$ & Total macroscopic inelastic strain tensor \\
\hline$E^{T}$ & Total macroscopic transformation strain tensor \\
\hline$\stackrel{\sim}{\varepsilon}$ & Total local strain tensor \\
\hline$\tilde{\sim}^{e}$ & Elastic local strain tensor \\
\hline$\tilde{\sim}^{\text {th }}$ & Thermal local strain tensor \\
\hline$\sim_{\sim}^{p}$ & Plastic local strain tensor \\
\hline$\stackrel{\sim}{\varepsilon}^{T}$ & Transformation local strain tensor \\
\hline$\xi^{T}$ & Mean Instantaneous Transformation Strain (MITS) tensor \\
\hline$\stackrel{\sim}{e}^{T}$ & Deviatoric part of the MITS tensor \\
\hline$\sum_{\sim}$ & Macroscopic stress tensor \\
\hline$\underset{\sim}{S}$ & Deviatoric part of the stress tensor \\
\hline$\underset{\sim}{\sigma}$ & Local stress tensor \\
\hline$\underset{\sim}{s}$ & Deviatoric part of the local stress tensor \\
\hline$\underset{\approx}{C}$ & Tensor of elastic moduli \\
\hline$\tilde{\alpha}^{\text {th }}$ & Thermal expansion tensor \\
\hline$\theta=\Delta V / V$ & Volume variation \\
\hline$f$ & Volume fraction of martensite within austenite \\
\hline$F^{\gamma}$ & Total volume fraction of austenite \\
\hline$F^{\alpha}$ & Volume fraction of ferrite \\
\hline$F^{B}$ & Volume fraction of bainite \\
\hline$D_{S}, D_{V}$ & Surface and volume dissipation \\
\hline$F_{f}$ & Driving force for martensitic transformation \\
\hline$\underline{\omega}$ & Velocity vector of the moving boundary \\
\hline$\overline{\gamma^{g}}$ & Slip amplitude on slip system $g$ \\
\hline$\stackrel{R}{\sim}^{g}$ & Schmid orientation tensor for slip system $g$ \\
\hline\langle\rangle & Averaging operator over the RVE \\
\hline RVE & Representative Volume Element \\
\hline$V, \partial V$ & Volume and boundary of the RVE \\
\hline MITS & Mean Instantaneous Transformation Strain \\
\hline
\end{tabular}

\section{Appendix B. Expression of the MITS} $s_{\sim}^{A}:$

The deviatoric part of the MITS (Eq. (74)) is expressed as a non-linear quadratic function of the stress deviator in austenite

$$
e_{i j}^{T}=\left(D_{i j k l}^{1}+\frac{1}{2} D_{i j k l m n}^{2} s_{m n}^{A}\right) s_{k l}^{A}
$$

For a isotropic function, tensors $D^{1}$ and $D^{2}$ depend only on five parameters $\left(d_{12}, d_{44}, d_{123}, d_{144}\right.$ and $\left.d_{244}\right)$.

$$
\begin{aligned}
& D_{i j k l}^{1}=d_{12} \delta_{i j} \delta_{k l}+2 \cdot d_{44} I_{i j k l} \\
& D_{i j k l m n}^{2}=d_{123} \delta_{i j} \delta_{k l} \delta_{m n}+6 \cdot d_{144} \delta_{(i j} I_{k l m n)}+4 \cdot\left(d_{244}-d_{144}\right) \delta_{i k} \delta_{l m} \delta_{n j}
\end{aligned}
$$

$d_{12}$ and $d_{44}$ are in $\mathrm{MPa}^{-1}, d_{123}, d_{144}$ and $d_{244}$ are in $\mathrm{MPa}^{-2}$.

$\delta_{(i j} I_{k l m n)}$ represents the symmetry with respect to indices $i$ and $j, k$ and $l, m$ and $n, i j, k l$ and $m n$. For example:

$$
\delta_{(i j} \delta_{l m} \delta_{n j)}=\frac{1}{4}\left(\delta_{i k} I_{j l m n}+\delta_{i l} I_{j k m n}+\delta_{i m} I_{k l n j}+\delta_{i n} I_{k l m j}\right)
$$


By inserting Eq. (B.2) in Eq. (B.1), the deviatoric part of the MITS is expressed by:

$$
e_{i j}^{T}=d_{12} s_{k l}^{A} \delta_{i j} \delta_{k l}+2 d_{44} I_{j k l} s_{k l}^{A}+\frac{d_{123}}{2} \delta_{i j} \delta_{k l} s_{k l}^{A} A_{m n}^{A} \delta_{m n}+3 d_{144} \delta_{(i j} I_{k l m n)} s_{k l}^{A} s_{m n}^{A}+2\left(d_{244}-d_{144}\right) \delta_{(i j} \delta_{l m} \delta_{n j} s_{k l}^{A} s_{m n}^{A}
$$

Since ${\underset{\sim}{s}}^{A}$ is a deviator, i.e. $s_{k k}^{A}=0$, the expression reduces itself to:

$$
e_{i j}^{T}=2 d_{44} s_{i j}^{A}+\frac{9}{16} d_{144} s_{k l}^{A} s_{k l}^{A} \delta_{i j}+\left[2\left(d_{244}-d_{144}\right)+\frac{27}{16} d_{144}\right] s_{k i}^{A} s_{k j}^{A}
$$

Since $e_{\sim}^{T}$ is also a deviatoric tensor, there is a condition on the parameters so that:

$$
d_{244}=-\frac{11}{16} d_{144}
$$

and the MITS can be expressed as:

$$
\bar{\xi}_{i j}^{T}=\frac{\theta}{3} \delta_{i j}+d_{1}^{\prime} s_{i j}^{A}+d_{2}^{\prime}\left(\frac{9}{16}\left[s_{k l}^{A} s_{k l}^{A}\right] \delta_{i j}-\frac{27}{16} s_{k i}^{A} s_{k j}^{A}\right)
$$

with

$$
\begin{aligned}
& d_{1}^{\prime}=2 \cdot d_{44} \\
& d_{2}^{\prime}=d_{144}
\end{aligned}
$$

Using this expression, the mechanical term $\underset{\sim}{\sigma^{A}}:{\underset{\sim}{\xi}}^{T}$ of the driving force for martensitic transformation (Eq. (58)) becomes:

$$
\sigma_{i j}^{A} \xi_{i j}^{T}=\left(s_{i j}^{A}+\frac{1}{3} \sigma_{p p}^{A} \delta_{i j}\right)\left(\frac{\theta}{3} \delta_{i j}+d_{1}^{\prime} s_{i j}^{A}+d_{2}^{\prime}\left(\frac{9}{16}\left[s_{k l}^{A} A\right] \delta_{k i j}^{A}-\frac{27}{16} s_{k i}^{A} s_{k j}^{A}\right)\right)
$$

By developing Eq. (B.9), the expression of the mechanical driving force is expressed such as:

$$
\sigma_{i j}^{A} \bar{E}_{i j}^{T}=I_{1} \frac{\theta}{3}+2 d_{1}^{\prime} J_{2}-\frac{81}{16} d_{2}^{\prime} J_{3}
$$

where $I_{1}, J_{2}$ and $J_{3}$ are the invariants of the average stress tensor in austenite and its deviatoric part defined as:

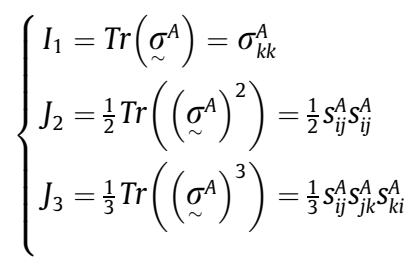

\section{Appendix C. Integral equation and concentration relations for the mean-field representation}

In order to calculate concentration tensors $\underset{\sim}{A}, a$ and $\underset{\sim}{\alpha}$ of Eq. (89) for a microscopically heterogeneous material, the necessary equations are:

- the balance equation in the quasi-static assumption with no body force

$$
\operatorname{div} \underset{\sim}{\sigma}=0
$$

- the compatibility equation in case of small strain assumption,

$$
\underset{\sim}{\dot{\varepsilon}}=\operatorname{grad}^{\mathrm{s}}(\underline{\dot{u}})
$$

- the local behaviour laws with martensitic transformation

$$
\underset{\sim}{\dot{\sigma}}(r)=\underset{\sim}{l e p}(r): \underset{\sim}{\dot{\varepsilon}}(r)-\underset{\sim}{n}(r) \cdot \dot{f}-\underset{\sim}{m}(r) \cdot \dot{T}
$$

where $\underset{\sim}{l^{e p}}$ is the elastoplastic tangent modulus and $\underset{\sim}{m}$ the thermal modulus.

$\underset{\sim}{n}$ is defined as: 


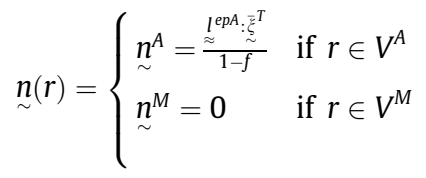

By combining Eqs. (C.1), (C.2) and (C.3), it results in:

$$
\left[l_{i j k l}^{e p}(r) \dot{u}_{k, l}(r)-n_{i j}(r) \cdot \dot{f}-m_{i j}(r) \cdot \dot{T}\right]_{j}=0
$$

To solve Eq. (C.5), fluctuations around a reference homogeneous material with properties $\underset{\sim}{e p 0}, \underset{\sim}{N^{0}}, M_{\sim}^{0}$ are considered:

$$
\begin{aligned}
& \underset{\sim}{l^{e p}}(r)=\underset{\sim}{L^{e p 0}}+\delta \underset{\sim}{l^{e p}}(r) \\
& \underset{\sim}{\sim}(r)=\underset{\sim}{N^{0}}+\delta \underset{\sim}{\sim}(r) \\
& \underset{\sim}{m}(r)={\underset{\sim}{M}}^{0}+\delta \underset{\sim}{m}(r)
\end{aligned}
$$

Inserting Eq. (C.6) in Eq. (C.5), one can obtain:

$$
L_{i j k l}^{e p 0} \dot{u}_{k, l j}+\left[\delta l_{i j k l}^{e p}(r) \dot{\varepsilon}_{k l}(r)-\delta n_{i j}(r) \cdot \dot{f}-\delta m_{i j}(r) \cdot \dot{T}\right]_{j}=0
$$

Eq. (C.7) can be solved using Green tensor $G$ for an infinite homogeneous media with property $L^{e p 0}$. The Green tensor is a second order tensor $G_{i j}$ used to determine the velocity at a point $r$ along direction $i$ when a coñcentrated force is applied at point $r^{\prime}$ along direction $j$.

By a derivative and integration by parts of Eq. (C.7), the local velocity is linked to the global one $\underline{\dot{U}}$ such as:

$$
\begin{aligned}
& \dot{u}_{m}(r)=\dot{U}_{m}+\int_{V^{\prime}} G_{m i j}\left(r-r^{\prime}\right)\left[\delta l_{i j k l}^{e p}(r) \dot{\varepsilon}_{k l}(r)-\delta n_{i j}(r) \cdot \dot{f}-\delta m_{i j}(r) \cdot \dot{T}\right] d V^{\prime} \\
& \dot{\varepsilon}_{m n}(r)=\dot{E}_{m n}+\int_{V^{\prime}} \Gamma_{m n i j}\left(r-r^{\prime}\right)\left[\delta l_{i j k l}^{e p}(r) \dot{\varepsilon}_{k l}(r)-\delta n_{i j}(r) \cdot \dot{f}-\delta m_{i j}(r) \cdot \dot{T}\right] d V^{\prime}
\end{aligned}
$$

where $\underset{\approx}{\Gamma}$ is the modified Green tensor defined as a function of $\underset{\sim}{G}$ by:

$$
\Gamma_{m n i j}=\frac{1}{2}\left(G_{m i . j n}+G_{n i . j m}\right)
$$

Eq. (C.9) is similar to the one obtained in case of thermoelastoplasticity where an additional stimuli associated to martensitic transformation via the tensor $n$ is considered. The solving of this equation uses the self-consistent approach (Berveiller, 1981) with the one site approximation where only the local part $\Gamma_{\sim}^{l}$ of $\Gamma_{\sim}$ is taken. If the effective material properties are considered, i.e. $\underset{\sim}{L^{0}}=L_{\sim}^{\text {eff }},{\underset{\sim}{n}}^{0}=n_{\sim}^{\text {eff }},{\underset{\sim}{0}}^{0}=m_{\sim}^{\text {eff }}$, Eq. (C.9) becomes:

$$
\dot{\varepsilon}_{m n}(r)=\dot{E}_{m n}+\Gamma_{m n i j}^{l}\left[\delta l_{i j k l}^{p e}(r) \dot{\varepsilon}_{k l}(r)-\delta n_{i j}(r) \cdot \dot{f}-\delta m_{i j}(r) \cdot \dot{T}\right]
$$

In the framework of thermoelastoplasticity with transformation, the strain concentration equation at a point $r$ is:

$$
\dot{\varepsilon}_{k l}(r)=A_{k l m n} \dot{E}_{m n}-A_{k l m n} \Gamma_{m n i j}^{l}\left[\delta n_{i j}(r) \cdot \dot{f}-\delta m_{i j}(r) \cdot \dot{T}\right]
$$

with

$$
A_{k l m n}=\left[I_{k l m n}-\Gamma_{k l p q}^{l}\left(l_{p q m n}^{e p}-L_{p q m n}^{e f f}\right)\right]^{-1}
$$

The general form of the concentration equation is:

$$
\dot{\varepsilon}_{k l}(r)=A_{k l m n} \dot{E}_{m n}+a_{k l} \cdot \dot{f}+\alpha_{k l} \cdot \dot{T}
$$

with:

$$
\begin{aligned}
& a_{k l}=-A_{k l m n} \Gamma_{m n i j}^{l}\left(n_{i j}-N_{i j}^{e f f}\right) \\
& \alpha_{k l}=-A_{k l m n} \Gamma_{m n i j}^{l}\left(m_{i j}-M_{i j}^{e f f}\right)
\end{aligned}
$$

\section{References}

Azzouz, F., Cailletaud, G., Antretter, T., Fischer, F.D., Tanaka, K., 2000. Transformation induced plasticity (TRIP) in steels subjected to non-monotonic loading paths - experiments and theory. Proceedings Plasticity, 175-177.

Berrahmoune, R., Berveiller, S., Inal, K., Patoor, E., 2006. Delayed cracking in 301LN austenitic steel after deep drawing: martensitic transformation and residual stress analysis. Materials Science and Engineering A, 262-266. 
Berveiller, M., Zaoui, A., 1981. Méthodes self consistantes en mécanique des solides hétérogènes, pp. 175-199.

Bowles, J., Mackenzie, J., 1954. The crystallography of martensite transformations. Acta Metallurgica 2, 129-147.

Bumbieler, F., 1999. Mise en évidence de l'effet TRIP sur un acier Fe-0.2C-1.5Mn-1.5Si - Comparaison avec un modèle micromécanique. Ph.D. Thesis, University of Metz.

Cherkaoui, M., Berveiller, M., Lemoine, X., 2000. Couplings between plasticity and martensitic phase transformation: overall behavior of polycrystalline TRIP steels. International Journal of Plasticity (16), 1215-1241.

Cherkaoui, M., Berveiller, M., Sabar, H., 1998. Micromechanical modelling of martensitic transformation induced plasticity (TRIP) in austenitic single crystals. International Journal of Plasticity 14 (7), 597-626.

Delannay, L., Jacques, P., Pardoen, T., 2008. Modelling of the plastic flow of TRIP-aided multiphase steel based on an incremental mean-field approach. International Journal of Solids and Structures 45, 1825-1843.

Diani, J., Berveiller, M., Sabar, H., 1995. Micromechanical modelling of the transformation induced plasticity (TRIP) phenomena in steels. International Journal of Engineering Science 33 (13), 1921-1934.

Duda, A., Paszkiewicz, T., 1999. Effective isotropic media for all Laue symmetry classes - construction of second and third order elastic constants. Physica B: Condensed Matter, 63-66.

Fischer, F., 1997. Modelling and simulation of transformation induced plasticity in elastoplastic materials. Mechanics of solids with phase changes, Eds Wien New York Springer, vol. 368, pp. 189-237.

Fischer, F., Schlögl, S., 1995. The influence of material anisotropy on transformation induced plasticity in steel subjected to martensitic transformation. Mechanics of Materials 21, 1-23.

Furnemont, Q., 2003. The micromechanics of TRIP-assisted multiphase steels. Ph.D. Thesis, Université Catholique de Louvain, Belgium.

Ganghoffer, J., Simonsson, K., 1998. A micromechanical model of the martensitic transformation. Mechanics of Materials 27, $125-144$.

Gautier, E., 1985. Ph.D. Thesis, Thèse d'Etat, INPL, Nancy.

Giusti, J., 1981. Contraintes et déformations résiduelles d'origine thermique, application au soudage et à la trempe des aciers. Ph.D. Thesis, University of Paris VI.

Hadamard, J., 1903. Leçons sur la propagation des ondes et les équations de l'hydrodynamique. Cours du Collège de France.

Hallberg, H., Håkansson, P.R.M., 2007. A constitutive model for the formation of martensite in austenitic steels under large strain plasticity. International Journal of Plasticity 23 (7), 1213-1239.

Hansel, A., Hora, P., Reissner, J., 1998. Description of strain induced martensitic phase transformation in metastable austenitic steels for the simulation of deep drawing processes at non-isothermal conditions. In: Proceedings IDDRG.

Hilding, D., Schedin, E., 2003. Implementation of a material model for TRIP-steels in LS-DYNA and comparison with test results. In: 4th LS-DYNA Users Conferences, Ulm, Germany.

Hourman, T., Hochard, J., Mess, G., 2000. Tech. rep., LEDEPP- Arcelor-Mittal.

Inoue, T., Arimoto, K., Ju, D., 1992. In: Proceedings of the First International Conference on Quenching and Control of Distortion, pp. $205-212$.

Iwamoto, T., Tsuta, T., Tomita, T., 1998. Investigation on deformation mode dependence of strain-induced martensitic transformation in TRIP steels and modelling of transformation kinetics. International Journal of Mechanical Sciences 40 (2-3), 173-182.

Iwamoto, T., Tsuta, T., 2000. Computational simulation of the dependence of the austenitic grain size on the deformation behavior of TRIP steels International Journal of Plasticity 16, 791-804.

Jacques, P., Furnemont, Q., Lani, F., Pardoen, T., Delannay, F., 2007. Multiscale mechanics of TRIP-assisted multiphase steels: I. Characterization and mechanical testing. Acta Materialia 55, 3681-3693.

Jaramillo, R., Lusk, M., 2004. Dimensional anisotropy during phase transformations in a chemically banded 5140 steel; Part II: modeling. Acta Materialia 52 (4), 859-867.

Jimenez, J., Carsi, M., Ruano, O., Frommeyer, G., 2009. Effect of testing temperature and strain rate on the transformation behaviour of retained austenite in low-alloyed multiphase steel. Materials Science and Engineering A 508 (1-2), 195-199.

Koistinen, D., Marburger, R., 1959. A general equation prescribing extent of austenite-martensite transformation in pure Fe-C alloys and plain carbon steels alloys and plain carbon steels alloys and plain carbon steels. Acta Metallurgica 7, 59-60.

Kouznetsova, V., Geers, M., 2008. A multi-scale model of martensitic transformation plasticity. Mechanics of Materials 40, 641-657.

Kröner, E., 1961. Zur plastischen verformung des vielkristalls. Acta Metallurgica 9, 155-161.

Kubler, R., Berveiller, M., Buessler, P., Lemoine, X., 2010. Semi phenomenological modelling of the behaviour of TRIP steels - application to sheet metal forming. In: Proceedings 13th ESAFORM Conference on Material Forming.

Kubler, R., Berveiller, M., Cherkaoui, M., Inal, K., 2003. Transformation textures in unstable austenitic steel. Journal of Engineering Materials and Technology $125,12-17$.

Kubler, R., Inal, K., Berveiller, M., 2002. Stress distribution in unstable austenitic steel. Materials Science Forum, 495-500.

Lani, F., Furnemont, Q., Jacques, P., Delannay, F., Pardoen, T., 2002. Micromechanical modeling of plastic anisotropy and strain induced phase transformation in dual-elastoplastic phase materials. In: Proceedings EMMC6, pp. 169-177.

Lebedev, A., Kosarchuk, V., 2000. Influence of phase transformations on the mechanical properties of austenitic stainless steels. International Journal of Plasticity 16, 749-767.

Leblond, J., 1989. Mathematical modelling of transformation plasticity in steels, II: coupling with strain hardening phenomena. International Journal of Plasticity 5, 573-591.

Leblond, J., Devaux, J., Devaux, J., 1989. Mathematical modelling of transformation plasticity in steels, I: case of ideal-plastic phases. International Journal of Plasticity 5, 551-572.

Lemaitre, J., Chaboche, J., 1985. Mécanique des Matériaux Solides, second ed. Dunod-Paris.

Levitas, V., 1998. Thermomechanical theory of martensitic phase transformations in inelastic materials. International Journal of Solids and Structures 35 (910), 889-940.

Lubarda, V., 1999. Apparent elastic constants of cubic crystals and their pressure derivatives. International Journal of Non-Linear Mechanics (34), 5-11.

Mahnken, R., Schneidt, A., Antretter, T., 2009. Macro modelling and homogenization for transformation induced plasticity of a low alloy steel. International Journal of Plasticity 25, 183-204.

Meftah, S., Barbe, F., Taleb, L., Sidoroff, F., 2007. Parametric numerical simulations of TRIP and its interaction with classical plasticity in martensitic transformation. European Journal of Mechanics A/Solids 26, 688-700.

Miller, M., McDowell, D., 1996. Modelling large strain multiaxial effects in FCC polycrystals. International Journal of Plasticity 12 (7), $875-902$.

Mori, T., Tanaka, K., 1973. Average stress in matrix and average energy of materials with misfitting inclusions. Acta Metallurgica 21, 571-574.

Niclaeys, C., Ben Zineb, T., Arbab-Chirani, S., Patoor, E., 2002. Determination of the interaction energy in the martensitic state. International Journal of Plasticity 18 (11), 1619-1647.

Olson, G., Cohen, M., 1975. Metallurgical Transaction 6A, 791-795.

Olson, G., Cohen, M., 1982. Stress assisted isothermal martensitic transformation: application to TRIP steels. Metallurgical Transactions A 13 A, 1907.

Patel, J., Cohen, M., 1953. Criterion for the action of applied stress in the martensitic transformation. Acta Metallurgica (1), 531.

Patoor, E., Berveiller, M., 1997. Micromechanical modeling of themoelastic behavior of shape memory alloys. CISM Lecture Notes (368), 121-188.

Petit, B., Gey, N., Cherkaoui, M., Bolle, B., Humbert, M., 2007. Deformation behavior and microstructure/texture evolution of an annealed 304 AISI stainless steel sheet.experimental and micromechanical modeling. International Journal of Plasticity 23, 323-341.

Petit-Grostabussiat, S., Taleb, L., Jullien, J., 2004. Experimental results on classical plasticity of steels subjected to structural transformations. International Journal of Plasticity 20 (8-9), 1371-1386. 
Reynolds, O., 1903. Ecol. model. Papers on Mechanical and Physical Subjects-The Sub-Mechanics of the Universe. CollectedWork, III, vol. 117. Cambridge University Press, pp. 41-64.

Sabar, H.B.M., Berveiller, M., 1991. The inhomogeneous and plastic inclusion problem with moving boundary. International Journal of Plasticity 7, 759-779.

Serri, J., Martiny, M., Ferron, G., 2005. Finite element analysis of the effects of martensitic phase transformation in TRIP steel sheet forming. International Journal of Mechanical Sciences 47 (6), 884-901.

Stringfellow, R., Parks, D., Olson, G., 1992. Acta Metallurgical Material 40, 1703.

Taleb, L., Sidoroff, F., 2003. A micromechanical modeling of the Greenwood-Johnson mechanism in transformation induced plasticity. International Journal of Plasticity 19 (10), 1821-1842.

Tjahjanto, D., Suiker, A., Turteltaub, S., Rivera Diaz del Castillo, P., van der Zwaag, S., 2007. Micromechanical predictions of TRIP steel behavior as a function of microstructural parameters. Computational Materials Science 41, 107-116.

Tomita, Y., Iwamoto, T., 1995. Constitutive modeling of TRIP steel and its application to the improvement of mechanical properties. International Journal of Mechanical Sciences 37, 1295-1305.

Tourki, Z., Bargui, H., Sidhom, H., 2005. The kinetic of induced martensitic formation and its effect on forming limit curves in the AISI 304 stainless steel. Journal of Materials Processing Technology 166, 330-336.

Turteltaub, S., Suiker, A., 2006. A multiscale thermomechanical model for cubic to tetragonal phase transformations. International Journal of Solids and Structures 43, 4509-4545.

Videau, J., Cailletaud, G., Pineau, A., 1994. Modélisation des effets mécaniques des transformations de phases pour le calcul de structures. Journal de Physique IV 4 (C3), 227-232.

Wang, Y.K.A., 1997. Three-dimensional field model and computer modeling of martensitic transformations. Acta Materialia 45 (2), 759-773.

Wechsler, M., Lieberman, D., Read, T., 1953. On the theory of the formation of martensite. Journal of Metals, Transactions on AIME, 1503-1515. 